\title{
Comparing orbiter and rover image-based mapping of an ancient sedimentary environment, Aeolis Palus, Gale crater, Mars
}

K. M. Stack ${ }^{1}$, C. S. Edwards ${ }^{2}$, J. P. Grotzinger ${ }^{3}$, S. Gupta ${ }^{4}$, D. Y. Sumner ${ }^{5}$, F. J. Calef, III ${ }^{1}$, L.A. Edgar $^{2}$, K. S. Edgett ${ }^{6}$, A. A. Fraeman ${ }^{3}$, S. R. Jacob ${ }^{7}$, L. Le Deit ${ }^{8}$, K. W. Lewis 9 , M. S. Rice ${ }^{10}$, D. Rubin $^{11}$, R. M. E. Williams ${ }^{12}$, K. H. Williford ${ }^{1}$

${ }^{1}$ Jet Propulsion Laboratory, California Institute of Technology, Pasadena, CA 91109, USA

${ }^{2}$ Astrogeology Science Center, United States Geological Survey, Flagstaff, AZ 86001, USA

${ }^{3}$ Department of Geological and Planetary Sciences, California Institute of Technology,

Pasadena, CA 91125, USA

${ }^{4}$ Department of Earth Science and Engineering, Imperial College, London, SW7 2AZ, UK

${ }^{5}$ Department of Earth and Planetary Sciences, University of California Davis, Davis, CA 95616, $U S A$

${ }^{6}$ Malin Space Science Systems, Inc., San Diego, CA 92191-0148, USA

${ }^{7}$ Department of Geology and Geophysics, University of Hawai'i at Manoa, Honolulu, HI 96822, USA

${ }^{8}$ Laboratoire de Planétologie et Géodynamique de Nantes, Université de Nantes, Nantes,

France

${ }^{9}$ Department of Earth and Planetary Sciences, Johns Hopkins University, Baltimore, MD, 21218, USA

${ }^{10}$ Department of Physics and Astronomy, Western Washington University, Bellingham, WA 98225, USA

${ }^{11}$ Department of Earth and Planetary Sciences, UC Santa Cruz, Santa Cruz, CA 95064, USA

${ }^{12}$ Planetary Science Institute, Tucson, AZ 85719, USA.

Email address: kathryn.m.stack@jpl.nasa.gov

Copyright 2015. All rights reserved. 
1 Keywords: Mars; Mars, surface; Geological Processes

3 Highlights

4 - Orbital facies were mapped at the Darwin, Cooperstown, and Kimberley waypoints in 5 Gale crater.

6 - Orbital maps were compared with ground-based observations from the Curiosity rover.

7 - Integrated orbital and rover observations are necessary to construct high fidelity 8 depositional models.

\section{Abstract}

11 This study provides the first systematic comparison of orbital facies maps with detailed

12 ground-based geology observations from the Mars Science Laboratory (MSL) Curiosity rover to

13 examine the validity of geologic interpretations derived from orbital image data. Orbital facies

14 maps were constructed for the Darwin, Cooperstown, and Kimberley waypoints visited by the

15 Curiosity rover using High Resolution Imaging Science Experiment (HiRISE) images. These

16 maps, which represent the most detailed orbital analysis of these areas to date, were compared

17 with rover image-based geologic maps and stratigraphic columns derived from Curiosity’s Mast

18 Camera (Mastcam) and Mars Hand Lens Imager (MAHLI). Results show that bedrock outcrops

19 can generally be distinguished from unconsolidated surficial deposits in high-resolution orbital

20 images and that orbital facies mapping can be used to recognize geologic contacts between well-

21 exposed bedrock units. However, process-based interpretations derived from orbital image

22 mapping are difficult to infer without known regional context or observable paleogeomorphic

23 indicators, and layer-cake models of stratigraphy derived from orbital maps oversimplify 
24 depositional relationships as revealed from a rover perspective. This study also shows that fine-

25 scale orbital image-based mapping of current and future Mars landing sites is essential for

26 optimizing the efficiency and science return of rover surface operations.

\section{Introduction}

Geologic maps provide a two-dimensional representation at the surface of the threedimensional spatial and temporal relationships of lithologic or chronostratigraphic units that

31 make up a planet's crust. For planets and other solar system bodies whose surfaces can only be

32 studied remotely via telescopic, flyby, orbital, airborne, lander, or rover observations,

33 photogeologic mapping is an important tool for providing insight into the geometric disposition

34 of geologic units and the evolution of planetary surfaces. Despite the increased sophistication

35 and spatial resolution of recent orbiter image-based geologic mapping efforts, considerable

36 uncertainties remain in the manners in which investigators gather their observations and interpret

37 orbiter image data [Wilhelms, 1990; Hansen, 2000; Tanaka et al., 2009].

Independent ground truth of orbital geologic interpretations is currently impossible for

39 most of the martian surface, but such comparisons can be made for the seven locations that have

40 been visited by rovers or landers: Chryse Planitia (Viking 1), Utopia Planitia (Viking 2), Ares

41 Vallis (Mars Pathfinder), Meridiani Planum and Gusev crater (Mars Exploration Rover (MER)

42 mission Opportunity and Spirit rovers, respectively), Vastitas Borealis (Phoenix Mars lander),

43 and Gale crater (Mars Science Laboratory (MSL) Curiosity rover). Orbiter and rover or lander

44 image-based comparisons can provide important insights into the fidelity of paleoenvironmental

45 interpretations made with these datasets by establishing a connection between "mega-scale"

46 orbital observations and those made on-site at the rover "macro- to micro-scale." Understanding 
47 the value-added nature of geologic investigations using multiple spatial scales is particularly

48 important for currently active rover missions like MSL and MER Opportunity which rely heavily

49 on orbital geologic interpretations to assist in science activity and traverse planning [Grotzinger

50 et al., 2014; Arvidson et al., 2014; Arvidson et al., 2015; Crumpler et al., 2011, 2015]. Future

51 missions including InSight, the European Space Agency (ESA) ExoMars 2018 rover, and the

52 Mars2020 rover will also use orbital image datasets and geologic interpretations of these datasets

53 to guide landing site selection. Orbiter and rover image-based comparisons can also be used to

54 extend geologic interpretations made from orbital data, particularly those regarding

55 paleoenvironment and past conditions for habitability, to elsewhere on the planet where ground-

56 truth observations are unlikely to be available.

57 Gale crater, landing site of the MSL Curiosity rover (Figure 1), provides an ideal place

58 for such a comparison given the variety of scales at which this location has been mapped from

59 images acquired from orbit [Malin and Edgett, 2000; Pelkey et al., 2004; Anderson and Bell,

60 2010; Milliken et al., 2010; Thomson et al., 2011; LeDeit et al., 2013; Calef et al., 2013; Rice et

61 al., 2013b; Grotzinger et al., 2014] and the sequence of sedimentary rocks present in Gale crater

62 now known to represent conditions favorable for past habitability [Grotzinger et al., 2014]. This

63 study presents orbital facies maps constructed from High Resolution Imaging Science

64 Experiment (HIRISE) images and interpreted cross-sections produced at a scale of 1:500 from

65 HiRISE images and digital terrain models (DTMs) for three major Curiosity rover field

66 investigation sites, waypoints informally named Darwin, Cooperstown and Kimberley (Figure

67 2). The rover team analyzed these waypoints during Curiosity's $\sim 10 \mathrm{~km}$ traverse across Bradbury

68 Rise from Yellowknife Bay to the base of Aeolis Mons [Vasavada et al., 2014]. The orbital

69 facies maps and cross-sections presented here, which represent the most detailed observations 
70 and interpretations based on orbital images of these areas to-date, are then compared to geology

71 observations derived from the Curiosity rover Mast Camera (Mastcam) and Mars Hand Lens

72 Imager (MAHLI) at each waypoint. In addition to providing a systematic comparison of orbiter

73 and rover image-based geologic observations and interpretations at each waypoint, this study

74 presents a critical examination of the validity and significance of geologic mapping and

75 stratigraphic interpretations made using remotely acquired orbiter image datasets. Conclusions

76 are drawn about the past depositional settings and paleoenvironments present in Gale crater

77 using correlations between rover and orbiter image data.

\section{Background}

Flyby and orbiter images of the martian surface acquired during the 1960s and 1970s by

81 the Mariner and Viking spacecraft enabled the creation of increasingly detailed and

82 comprehensive geologic maps such as those by Scott and Carr [1978], Scott and Tanaka [1986],

83 Greeley and Guest [1987], and Tanaka and Scott [1987]. Geologic maps based on Mariner 9 and

84 Viking data remained state-of-the-art until the early 2000s when a series of high-resolution

85 orbital imaging systems onboard Mars Global Surveyor (MGS), Mars Odyssey, Mars Express,

86 and the Mars Reconnaissance Orbiter (MRO) acquired thermal, visible, and near-infrared images

87 of the martian surface that have enabled detailed local and regional geologic mapping efforts

88 down to the sub-meter scale (e.g., Rice et al. [2013a], Okubo [2014], and Sun and Milliken

89 [2014], among many others). Analysis of these recent datasets has also led to refinements and

90 updates to a global geologic map of Mars [Tanaka et al., 2014].

91 The Viking 1 and 2 landers afforded the first opportunity to ground-truth orbital geologic

92 map interpretations of Mars [Binder et al., 1977; Mutch et al., 1977; Sharp and Malin, 1984; 
93 Jakosky and Christensen, 1986; Crumpler et al., 2001; Thomson and Schultz, 2007]. Nearly

94 twenty years later came confirmation of orbital interpretations at the Ares Vallis landing site for

95 the Pathfinder mission [Komatsu and Baker, 1997; Rice and Edgett, 1997, Smith et al., 1997].

96 The landing site selection process for the MER Spirit and Opportunity was the first to take

97 advantage of meter-scale high-resolution image data provided by MGS and Mars Odyssey

98 [Golombek et al., 2003]. Subsequent to landing, Golombek et al. [2005] and [2006] addressed

99 inconsistencies between orbital geologic interpretations and observations of in situ geochemistry

100 and depositional environments observed with the MER Opportunity and Spirit rovers. Beginning

101 in late 2006, Spirit and Opportunity surface science operations made use of images from the

102 HiRISE camera onboard MRO as a tool for geologic interpretation and mission planning

103 [Arvidson et al., 2006; Golombek et al., 2006; Wray et al., 2009; Wiseman et al., 2010; Crumpler

104 et al., 2011, 2015; Arvidson et al., 2015]. The Phoenix Lander mission which launched in 2007

105 also made use of HIRISE images during the selection and hazard evaluation of its landing site in

106 the northern plains of Mars [Arvidson et al., 2008; Golombek et al., 2008; Seelos et al., 2008].

107 The MSL mission is the first rover mission to use HiRISE orbital images during the landing site

108 selection process [Anderson and Bell, 2010; Golombek et al., 2012; Grotzinger et al., 2012; Rice

109 et al., 2013a], and HiRISE image-based mapping of the Gale crater ellipse has provided critical

110 context for Curiosity rover observations since landing [Calef et al., 2013; Rice et al., 2013b;

111 Grotzinger et al., 2014; Arvidson et al., 2014].

112

\section{2.1. Previous Orbiter Image-Based Mapping of the MSL Curiosity Landing Ellipse}

114 The main focus of previous mapping studies of Gale crater has been on the strata of

115 Aeolis Mons, the $\sim 5 \mathrm{~km}$-thick mound in the center of the crater [Malin and Edgett, 2000; 
116 Milliken et al., 2010; Thomson et al., 2011; Zimbelman and Scheidt, 2012]. Prior to Curiosity's

117 landing in Gale crater, only Anderson and Bell [2010] published a geologic map of the MSL

118 landing ellipse, a $20 \mathrm{~km}$ by $7 \mathrm{~km}$ ellipse positioned on Aeolis Palus, the plains surrounding

119 Aeolis Mons. Since landing, Le Deit et al. [2013], Calef et al. [2013], Rice et al. [2013b],

120 Sumner et al. [2013], and Grotzinger et al. [2014] have mapped some or all of the area covered

121 by the MSL landing ellipse at varying scales and levels of detail.

122 Anderson and Bell [2010] mapped the area covered by the MSL landing ellipse, including

123 the three areas explored in this study, using MRO Context Camera (CTX) images (6 m/pixel).

124 Although the map scale was not explicitly stated in the study, they mapped with a focus on

125 geologic features and stratigraphic relationships observable at a scale of hundreds of meters to

126 kilometers. Over the area of Aeolis Palus traversed by the Curiosity rover, Anderson and Bell

127 [2010] mapped two geomorphic units: a hummocky plains unit and a mound-skirting unit. The

128 three areas examined in this study were mapped as part of the hummocky plains unit. The

129 hummocky plains unit was described as "hummocky terrain of smoothly-varying thermal inertia"

130 with a fairly uniform albedo in CTX images and was interpreted by Anderson and Bell [2010] to

131 represent largely unconsolidated material transitioning to fractured bedrock. Sinuous ridges

132 locally found on this unit were interpreted as inverted fluvial channels, but no other indicators of

133 geologic process were described. The mound-skirting unit, which was interpreted to be younger

134 than the hummocky plains unit, was described as an erosion-resistant, mesa-forming geologic

135 unit, the surface of which shows many small pits and ridges interpreted to be largely fluvial and

136 eolian in origin.

137 Le Deit et al. [2013] produced a geologic map of the entire interior of Gale crater using

138 Mars Express High Resolution Stereo Camera (HRSC), CTX, and HiRISE images and HRSC 
139 DTMs to construct cross-sections across large swaths of the crater interior. They distinguished

140 several "crater floor" units, although all of Bradbury Rise traversed by the Curiosity rover was

141 mapped as a single crater floor unit (Cf1). The Cf1 unit extends from the northern crater rim to

142 the base of Aeolis Mons and was interpreted to represent fluvial, alluvial, and colluvial

143 deposition in a bajada complex located downstream from valleys incised into the northern rim of

144 Gale crater. The Cf1 unit was interpreted to be younger than the lowest strata of Aeolis Mons,

145 but likely older than most of the upper mound strata.

146 A detailed mapping effort focused on the MSL landing ellipse was presented in

147 Grotzinger et al. [2014] (Figure 3), summarizing the preliminary efforts of Calef et al. [2013],

148 Rice et al. [2013b], and Sumner et al. [2013]. Prior to Curiosity's landing, the MSL science team

149 undertook mapping using HiRISE images and DTMs derived from HiRISE stereo via the

150 methods of Kirk et al. [2008]. The main objectives were to guide initial traverse planning after

151 the rover landed and to provide context and guidance for subsequent traverse and science

152 investigation planning. Through this effort, the landing ellipse was subdivided into six geologic

153 units: alluvial fan (AF), bedded fractured (BF), cratered surface (CS), hummocky plains (HP),

154 rugged terrain (RT), and striated (SR). The Curiosity rover encountered bedrock mapped as the

155 BF unit in Yellowknife Bay [Grotzinger et al., 2014; Arvidson et al., 2014], but the terrain across

156 which the rover traversed to the base of Mount Sharp was mapped primarily as HP and RT, with

157 intermittent exposures of CS and SR [Calef et al., 2013; Rice et al., 2013b; Arvidson et al., 2014;

158 Grotzinger et al., 2014; Vasavada et al., 2014]. The HP unit exhibits low surface roughness,

159 uniform tone, and decimeter-scale topographic hummocks [Grotzinger et al., 2014] and

160 corresponds generally to Anderson and Bell's [2010] hummocky plains unit. The RT unit was

161 identified in HiRISE images as isolated exposures throughout the first third of the traverse to 
162 Aeolis Mons, although larger $\left(100 \mathrm{~s} \mathrm{~m}^{2}\right)$, more continuous exposures of RT were mapped in the

163 southern part of the landing ellipse. The RT is characterized by its brightness relative to

164 surroundings, topographic variability, meter to decameter-scale surface roughness, and contains

165 erosion-resistant scarps [Grotzinger et al., 2014]. The CS unit is characterized by sub-planar

166 surfaces containing a relatively high density of sub-kilometer diameter impact craters that occur

167 at different elevations throughout the landing ellipse [Grotzinger et al., 2014; Jacob et al.,

168 submitted]. The RT and CS units described in Grotzinger et al. [2014], though mapped in greater

169 detail, correspond generally to the mound-skirting unit of Anderson and Bell [2010]. Exposures

170 of the SR unit occur exclusively in the south central portion of the landing ellipse, and consist of

171 isolated light-toned outcrops exhibiting distinct northeast-southwest trending lineations visible in

172 high-resolution orbital images [Grotzinger et al., 2015]. Relative age relationships between the

173 HP, RT, CS, and SR unit are often ambiguous, and Rice et al. [2013b] acknowledged that these

174 units, particularly the RT and CS units, may represent distinct textural or geomorphic surface

175 expressions rather than stratigraphic units that can be projected into the subsurface.

\section{2.2. Curiosity's Traverse of Bradbury Rise}

178 Upon landing on Aeolis Palus in August of 2012, the Curiosity rover traversed east from

179 Bradbury Landing to an embayment of rock outcrop called Yellowknife Bay [Grotzinger et al.,

180 2014] (Figure 2). Before Curiosity's departure from Yellowknife Bay toward the base of Aeolis

181 Mons in July of 2013, the MSL team selected several waypoints along the planned traverse path

182 across Bradbury Rise, a topographic high that extends north several kilometers from the base of

183 Aeolis Mons to the distal end of the present-day Peace Vallis fan [Vasavada et al., 2014;

184 Arvidson et al., 2014] (Figures 1 and 2). These three waypoints: Darwin, Cooperstown, and 
185 Kimberley, were selected at approximately equidistant spacing along the planned route using

186 HiRISE images and the orbital geologic map of Calef et al. [2013] [Vasavada et al., 2014]

187 (Figure 2a, Table 1). The Darwin site was chosen because of the presence of a conspicuous $\sim 200$

188 m diameter sub-circular outcrop of bright bedrock amid the hummocky plains of Bradbury Rise

189 (Figure 2b). Similar isolated occurrences of bright bedrock were observed in HiRISE images

190 throughout Bradbury Rise and the Darwin waypoint was chosen as a representative of these

191 outcrops [Vasavada et al., 2014]. The Cooperstown area (Figure 2c) was selected for study based

192 on the presence of a variety of bright outcrops observed in HiRISE images, some of which

193 exhibited meter-scale polygonal forms bounded by fractures that appeared similar in the HiRISE

194 images to fracture-delineated polygonal forms in the fine-grained sedimentary rocks observed at

195 Yellowknife Bay. These waypoints served as intermediate stops between Yellowknife Bay and

196 the third waypoint, Kimberley (Figure 2d). The Kimberley area attracted interest early in the

197 mission due to the presence in HiRISE images of a layered stratigraphy expressed by differential

198 erosion of the terrain. Some outcrop exposures in this area of the ellipse contained striations,

199 regularly spaced linear features extending tens of meters in length, that were particularly

200 distinct from other outcrops observed in the landing ellipse region [Grotzinger et al., 2014;

201 Grotzinger et al., 2015]. It was anticipated that an imaging and geochemical analysis campaign

202 would help determine the origin of the striated outcrops, as well as their relationship with the

203 nearby hummocky terrain and overlying bedded rocks [Vasavada et al., 2014; Grotzinger et al.,

204 2015].

205

The MSL team also acquired opportunistic remote sensing and contact science

206 observations of float rocks, outcrops, eolian deposits, and regolith in between each of the three

207 waypoints described above. However, the orbiter and rover image-based observations at Darwin, 
208 Cooperstown, and Kimberley are broadly representative of the geology observed during the

209 traverse across Bradbury Rise (Figures 4-15), and also provide the best opportunities for direct

210 comparison due to the exposures of bedrock and surficial deposits that can be resolved and

211 distinguished in HiRISE images.

\section{3. Data and Methods}

\section{$214 \quad 3.1$ Orbital Facies Mapping}

215 Maps based on planetary orbital image datasets most commonly use the terms "geologic

216 unit" or "geomorphic unit" to refer to the two-dimensional surface areas bounded by drawn

217 contacts. These terms are sometimes used interchangeably in planetary mapping, although

218 conventional planetary mapping guidelines offer clear distinctions. According to Wilhelms

219 [1990], a geologic unit is distinguished in planetary image data by its topographic expression and

220 remotely observed surface properties, and refers to a "sheetlike, wedgelike, or tabular body of

221 rock that underlies the surface.... and not a surface, a geomorphic terrain, or a group of

222 landforms." As part of the most recent global geologic mapping effort for Mars, Tanaka et al.

223 [2014] define geologic map units as "temporally unique geologic materials of substantial

224 thickness and extent for portrayal at map scale," and use primary formational morphology,

225 brightness and/or albedo, and spatial, stratigraphic, and relative crater age relationships to

226 delineate units. Materials interpreted to be surficial in nature or features interpreted to be the

227 result of secondary modification processes are not mapped as units.

228 Others prefer the term "geomorphic unit" in a planetary mapping context (e.g., Anderson

229 and Bell [2010], Sun and Milliken [2014]). Use of the term "geomorphic unit" generally avoids

230 the three-dimensional geometrical interpretation, implicit assumption of "rock" as opposed to 
231 unconsolidated surface materials, interpretation of primary formational versus secondary

232 modification features, temporal implications, or other exclusions implied by the Wilhelms [1990]

233 or Tanaka et al. [2014] definitions in favor of a more generic terminology. However, definitions

234 for "geomorphic unit" vary widely across the terrestrial and planetary literature and in the

235 context of terrestrial mapping, a geomorphic unit is most commonly used to refer to a landform

236 or group of landforms whose shape, structure, dimensions, or characteristics are indicative of a

237 common process (e.g., Haskins et al. [1998]).

238 In this study, the term "orbital facies" is used instead of "geologic unit" or "geomorphic

239 unit" since designations and subdivisions made from orbital visible-range images here were

240 based solely on variable brightness, local-scale color hue (spectral) variability, and surface

241 texture at a local and small scale [Grotzinger and Milliken, 2012]. Orbital facies mapped using

242 HiRISE images may indeed be geologic or geomorphic units according to the definitions

243 employed by Wilhelms [1990], Tanaka et al. [2014], or others and can be interpreted as such

244 with supporting observations particularly from topographic (i.e., interpretive geologic cross-

245 sections) or ground-based rover datasets. However, the reason for using the term "orbital facies"

246 here (sensu Grotzinger and Milliken [2012]) is to clarify that surface areas distinguished locally

247 at the fine scale employed during this study's mapping can, but need not have three-dimensional

248 geometry, substantial thickness, a common formation process, a temporal association, nor must

249 they represent lithified bedrock. Such an objective approach also prevented the need to

250 distinguish primary depositional from secondary modification features during orbiter image-

251 based mapping where such interpretations would have been uncertain and speculative.

252 Orbital facies maps at the 1:500 scale were produced for each waypoint using a $240 \mathrm{~m}$ by

$253360 \mathrm{~m}$ rectangular area around the Darwin, Cooperstown, and Kimberley waypoints, 
254 respectively, using $25 \mathrm{~cm} /$ pixel HiRISE color and gray-scale images (Figures 2 and 3). The

255 intention of mapping at this scale was to enable orbital facies distinctions of the finest level of

256 detail possible with orbital images for comparison with rover observations. Orbital facies

257 contacts were mapped as shapefiles on equidistant cylindrical-projected grayscale and color

258 HiRISE mosaics in ArcGIS. To test whether orbital facies represented stratigraphic units that

259 could be reasonably projected into the subsurface, interpretive cross-sections were constructed

260 for each waypoint using topographic profiles across the mapping area of each waypoint extracted

261 from DTMs created by the HiRISE team for the MSL project [Kirk et al., 2008; Golombek et al.,

262 2012; Calef et al., 2013] (Figures 4, 8, 12). Although a number of subsurface interpretations are

263 likely possible for each cross-section, an attempt was made to present straightforward

264 interpretations assuming approximately horizontal strata and superposition (younger strata

265 overlie older strata) since structural features indicating otherwise were generally lacking in the

266 study areas.

267 The gray-scale visual and topographic basemaps providing coverage over the study areas

268 were made from twelve HiRISE $25 \mathrm{~cm} /$ pixel stereo pairs that were processed, georeferenced, and

269 projected via the methods of Calef et al. [2013] to create a visible mosaic and a DTM with $1 \mathrm{~m}$

270 grid spacing and absolute elevations tied to Mars Orbiter Laser Altimeter (MOLA) data. The

271 processing of the HiRISE color mosaic used throughout this work (Figure 3) to aid in orbital

272 facies mapping interpretations was performed using a combination of the Integrated Software for

273 Imaging Spectrometers (ISIS) (e.g., Anderson et al. [2004]; Edmundson et al. [2012]) and the

274 DaVinci software packages (http://davinci.asu.edu). Color images were tied and projected to

275 existing basemaps via a series of manually and automatically chosen ground control points used

276 to update the spacecraft and camera pointing [Edmundson et al., 2012]. Prior to map projection, 
277 the images were normalized for CCD-to-CCD variations within a single image. After map

278 projection, the data were normalized for image-to-image variations to account for spatial and

279 temporal variations such as illumination and observing geometry as well as atmospheric opacity.

280 An across-track filter was used to remove any additional across-track image slope, and the

281 normalized radiance data were stretched using a running (or moving-window) histogram stretch

282 following the techniques described by Edwards et al. [2011]. This specialized stretch is

283 designed to emphasize local-scale morphology and color variations by maximizing the dynamic

284 range on a $\sim 5000 \times 5000$ pixel segment of the image and also serves to remove any residual

285 regional influence [Edwards et al., 2011]. The resulting color HiRISE mosaic highlights the

286 local-scale color (spectral) variability, where blue-purple hues commonly indicate mafic

287 materials (e.g., sand dunes, blocks) and neutral colors (e.g., gray) indicate dustier terrains.

\subsection{Rover Image-Based Geologic Mapping}

Prior to Curiosity's arrival at each waypoint stop, the focusable Mastcam M-100 (100

$291 \mathrm{~mm}$ fixed focal length) camera was used to acquire context mosaics. In this study, one mosaic

292 was chosen for each waypoint that provided a "rover's eye view" of as much of the orbital

293 mapping area as possible (Figures 6, 10, and 13). Each of the waypoint mosaics was white-

294 balanced and perspective projected. Mosaics were used to map visible distinctions that fall into

295 three general categories: bedrock lithology, unconsolidated surficial deposits, and

296 undifferentiated bedrock and surficial deposits (Figures 5, 6c, 10c, 13c). Bedrock boundaries

297 define areas in which a particular lithology dominates and include conglomerates and sandstones

298 of varying bedding characteristics (Figure 5). Although pixel scale varies within each mosaic and

299 between mosaics, the mosaic pixel scale is generally on the order of $\sim 1 \mathrm{~cm} /$ pixel or better for the 
300 majority of outcrop visible within each scene, permitting distinctions between outcrops of

301 conglomerate and those containing sand-sized or finer grains as well as the identification of

302 macroscopic textural elements such as vugs and platy versus apparently massive beds.

303 Unconsolidated surficial deposits include sand (e.g., Figure 5c), accumulations of float (e.g.,

304 Figure $5 \mathrm{f}$ ), defined here as loose pebble- to boulder-sized rocks not clearly connected to an

305 outcrop, and undifferentiated sand and float (e.g., Figure 5i). Where subdivisions are difficult to

306 define due to image resolution or viewing geometry, the bedrock or unconsolidated deposit is

307 designated as "undifferentiated." "Undifferentiated" examples include bedrock outcrops where

308 multiple lithologies are finely inter-bedded (e.g., Figure 5a), where bedrock is intermittently

309 exposed amongst other materials like sand or float, or where sand and float are intermixed (e.g.,

310 Figure 5i). As was the case for the orbital facies mapped from the HiRISE images, the outcrop

311 lithologies and surficial deposits mapped in the rover mosaics can, but do not necessarily,

312 represent distinct stratigraphic or geomorphic units.

313 To enable the comparison between orbiter and rover image-based observations, the

314 distribution of orbital facies for each waypoint was mapped on the corresponding rover mosaics

315 by identifying key landmark features in both the Mastcam mosaics and HiRISE images (Figures

316 6b, 10b, 13b). This mapping was done manually in ArcGIS by performing feature matching

317 between the HiRISE image of each waypoint projected in ArcGIS viewed side-by-side with the

318 corresponding Mastcam mosaic, which was displayed but not projected in a separate ArcGIS

319 project. Landmarks such as boulders, scarps, and sand dunes visible in both the Mastcam

320 mosaics and HiRISE images were used as aids in the placement of orbital facies boundaries on

321 the Mastcam mosaics. Foreshortening and the different viewing geometry between orbital and

322 ground-based images complicates the translation of orbital facies mapped in plan-view onto the 
323 rover mosaics, so the distribution of orbital facies mapped on rover mosaics should be

324 considered approximate, though generally faithful to the corresponding locations mapped on

325 HiRISE images. A quantitative, automated comparison of the orbital and rover surface maps

326 would have been possible if this study had used Mastcam orthophotos for which the geographic

327 location of each pixel within the mosaics was known. Unfortunately, the workflow required to

328 create Mastcam orthophotos is not supported by existing MSL mission tools and it was

329 considered out of the scope of the present study to develop new software to facilitate such a

330 quantitative analysis.

331 The stratigraphy for each waypoint was determined using observations of lithology,

332 texture, and fabric gleaned from Mastcam M-100 and M-34 mosaics and MAHLI images

333 (Figures 5, 7, 11, and 14). To construct the stratigraphic columns in Figure 15, contact science

334 locations were localized in HiRISE images relative to the rover traverse and distinctive features

335 visible in both rover mosaics and orbital images. Elevation values for the top and bottom of each

336 outcrop were then extracted from the HiRISE DTM and matched with georeferenced rover stereo

337 mosaics from the Curiosity navigation cameras (Navcam) [Maki et al., 2012] to calculate outcrop

338 thickness. Changes in bedding, grain-size, and erosional profile observed in the Mastcam and

339 MAHLI images were then plotted in a stratigraphic column for each contact science location

340 (Figure 15). The corresponding orbital facies projected as stratigraphic units were plotted

341 alongside each rover image-based stratigraphic column (Figure 15).

342 Vasavada et al. [2014] provided an overview of the outcrop characteristics observed at

343 both the Darwin and Cooperstown waypoints. This study expands on those results, presenting the

344 first annotated rover image-based mosaics and stratigraphic columns for the express purpose of

345 making direct comparisons between rover and orbiter geologic interpretations. 


\section{4. Orbiter and Rover Image-Based Mapping}

\section{4.1. Darwin}

\section{$349 \quad$ 4.1.1 Orbital Facies}

350 Five orbital facies were mapped at the Darwin waypoint: smooth dark, smooth

351 hummocky, boulder hummocky, resistant cratered outcrop, and bright outcrop orbital facies

352 (Figure 4). The resistant cratered outcrop orbital facies and the bright outcrop orbital facies are

353 interpreted to represent lithified bedrock characterized by the presence of small scarps, visible

354 stratification, and in a few locations the retention of craters. The bright outcrop orbital facies is

355 characterized by its distinct brightness visible in the gray-scale HiRISE image compared to the

356 surrounding terrain (Figures $2 \mathrm{~b}$ and 3 ). This orbital facies exhibits meter-scale variations in

357 surface texture indicated by apparent changes in brightness and/or shadows, meter-scale

358 polygonal fracture forms visible on planar surfaces, and bright and dark alternations suggestive

359 of bedding, although these textures are not ubiquitous throughout the entire exposure of this

360 orbital facies. The bright outcrop orbital facies appears white and tan in the HiRISE color mosaic

361 and exhibits color variation likely caused by the presence of float blocks or accumulations of

362 windblown mafic sand on the outcrop. The bright outcrop orbital facies occurs primarily in the

363 sub-circular plan-form feature at the center of the mapping area, although several occurrences of

364 bright outcrop are mapped within the surrounding smooth hummocky orbital facies. The resistant

365 cratered outcrop orbital facies is distinguished by the presence of impact craters that have

366 diameters at decimeter-scale, a variable surface texture suggested by the meter-scale changes in

367 relative brightness and color hue, and accumulations of dark boulders on the scarps that 
368 demarcate the boundaries of this unit. This orbital facies forms a scarp-forming capping material 369 expressed at the tops of local topographic highs.

370 The smooth dark, boulder hummocky, and smooth hummocky orbital facies contain

371 visible boulders and lack well-defined scarps, bedding, or craters. For these reasons, these three

372 orbital facies are interpreted to represent unconsolidated surficial deposits. The smooth

373 hummocky orbital facies is mapped predominantly in the area surrounding the sub-circular bright

374 outcrop in the center of the study area, and is characterized by a generally uniform brightness

375 and decimeter-scale hummocky topography (Figure 2b). In the HiRISE color mosaic (Figure 3),

376 this orbital facies appears tan to brown in color indicating that it may include a layer of surface

377 dust. The boulder hummocky orbital facies appears similar in morphology to the smooth

378 hummocky orbital facies, but contains accumulations of dark boulders resolvable in HiRISE

379 images and occurs in decimeter-scale areas within the bright outcrop orbital facies. The smooth

380 dark orbital facies is mapped and distinguished primarily with the aid of the HiRISE color

381 mosaic as it is characterized by a distinctly blue hue consistent with the presence of mafic

382 materials (e.g., basaltic sands). This facies occurs in topographic lows and is interpreted as

383 unconsolidated basaltic sand.

384 Two possible cross-sectional interpretations of the Darwin orbital facies projected into

385 the sub-surface as stratigraphic units are presented in Figure $4 b$ and $4 c$. In Figure $4 b$, the bright

386 outcrop orbital facies is interpreted as the infill of a bowl-shaped basin whose substrate material

387 is composed primarily of the smooth hummocky facies. The bright outcrop orbital facies, which

388 occurs both in the basin and outside it, might represent erosional remnants of a more continuous

389 layer. In this scenario, the smooth hummocky orbital facies is the oldest of the five facies. The

390 resistant cratered outcrop, boulder hummocky, and smooth dark orbital facies were deposited 
391 after the bright outcrop orbital facies. This stratigraphic model is particularly compelling because

392 it is consistent with the interpretation that the Darwin basin is a filled impact crater, which

393 matches the sub-circular shape of the bright outcrop orbital facies.

394 In the second interpretation (Figure 4c), the bright outcrop orbital facies is interpreted as

395 a through-going horizontal layer in the subsurface rather than as a basin fill. In this model, the

396 resistant cratered outcrop orbital facies directly overlies the bright outcrop orbital facies. This

397 model is consistent with the interpretation of the smooth hummocky, smooth dark, and boulder

398 hummocky orbital facies as relatively thin, discontinuous accumulations of surficial deposits

399 overlying both the bright outcrop and resistant cratered outcrop orbital facies. Distinguishing

400 between these two interpretations is difficult from orbital-based mapping alone, but rover image-

401 derived observations, particularly of the areas mapped as smooth hummocky facies and bright

402 outcrop facies, may be helpful in resolving the Darwin stratigraphy.

\section{4.1.2 Rover Image-Based Geologic Mapping}

404 The M-100 Mastcam mosaic of the Darwin waypoint shows a landscape dominated by

405 exposures of conglomerate and sandstone bedrock overlain by localized sand drifts and fields of

406 float (Figures 5a-c, 6, and 7). Several conspicuous accumulations of dark float of a fine-grained

407 lithology are observed in the mosaic, predominantly occurring on local topographic highs.

408 Extending across the center of the mosaic is a topographic depression containing bedded and

409 resistant thin-bedded sandstone outcrops and the occasional coarser-grained conglomerate bed

410 exposed amongst undifferentiated accumulations of sand and float (Figure 6c). Sandstone beds

411 observed along the edges of the depression appear to dip toward the center of the basin such that

412 the dip varies systematically around the depression, while outcrops near the middle of the basin

413 show nearly horizontal dips. The bright exposure of undifferentiated sandstone and conglomerate 
414 and float present on the northwestern edge of the basin (Figure 6c, blue box) is the location of

415 contact science activities performed by Curiosity. Mastcam and MAHLI images of this outcrop

416 allow additional detail to be resolved (Figure 7), and lithology and grain size changes within the

417 outcrop are documented in detail in the stratigraphic column in Figure 15a. A basal pebble

418 conglomerate (Figure $7 \mathrm{~b}$ ) is overlain by a $\sim 50 \mathrm{~cm}$-thick layer of very coarse sandstone (Figure

419 7c) containing pebble-rich lenses (Figure 7a). A discontinuous wedge of a cobble-bearing

420 conglomerate overlies the sandstone interval and thin lenses of platy sandstone occur within this

421 coarser-grained interval (Figure 7a). These platy lenses occur in both horizontal and vertical

422 orientations. A $\sim 1.5$ m-thick interval of massive granule conglomerate fines upward to coarse

423 sandstone and overlies the cobble conglomerate. The section is capped by an accumulation of

424 dark float of an apparent fine-grained lithology (Figure 7a).

\section{4.1.3 Comparison between Orbiter and Rover Image-Based Mapping}

426 As expected, a comparison of the mapped distributions of orbital facies and rover image-

427 based geology (Figure 6b and 6c) shows the increased level of detail and distinction possible

428 with rover images. In addition, the rover image-based observations permit the identification of

429 specific bedrock lithologies (e.g., sandstone and conglomerate), rock type (i.e., sedimentary), and

430 a confirmation of whether surface exposures represent lithified bedrock or unconsolidated

431 surficial deposits. The smooth hummocky orbital facies, interpreted from orbital images as a

432 likely unconsolidated deposit, is observed on the ground to be composed of in-place sandstone

433 and conglomerate outcrop intermixed with float blocks. Although the presence of in-place

434 outcrop was not resolvable in the HiRISE image of the smooth hummocky orbital facies, there is

435 a fairly good correlation between this orbital facies and areas mapped as either float or

436 undifferentiated sandstone and conglomerate. 
The resistant cratered outcrop facies also exhibits a fairly consistent correlation with

438 accumulations of dark float exposed at the top of local topographic highs. However, the rover

439 mosaic shows that the resistant cratered outcrop orbital facies does not appear to correspond to

440 bedrock, but rather surficial concentrations of float blocks. There is a generally good correlation

441 between the mapped distribution of the smooth dark orbital facies and areas containing higher

442 proportions of sand or undifferentiated sand and float. This correlation is particular apparent

443 within the central depression at Darwin and is consistent with the orbital interpretation of the

444 smooth dark orbital facies as a surficial deposit containing windblown sand. The bright outcrop

445 orbital facies also corresponds fairly well with sandstone outcrops observed in Curiosity rover

446 images, although the annotated rover mosaic shows the sandstone to be less extensive than the

447 orbital mapping would indicate due to the presence of surficial sand and float (Figure 6c). Areas

448 of bright outcrop orbital facies at the contact science location correspond to an exposure of

449 undifferentiated sandstone and conglomerate containing little surficial sand or float cover and

450 which appears to be coarser-grained than the sandstones cropping out in the central depression.

451 The weakest correlation between an orbital facies and rover geologic mapping is seen with the

452 boulder hummocky orbital facies, which fails to correspond directly to any unique lithology or

453 surficial deposit observed in the rover mosaic. In the HiRISE image, the boulder hummocky

454 orbital facies is distinguished primarily by the presence of resolvable boulders, but when these

455 areas are observed on the ground in the Mastcam mosaic, the presence of in-place sandstone and

456 conglomerate outcrop becomes the primary characteristics by which these areas are

457 distinguished.

458 The rover image-based observation that the smooth hummocky facies is at least partially

459 composed of in-place bedrock rather than being composed completely of unconsolidated float 
460 and sand is consistent with the cross-sectional model presented in Figure $4 \mathrm{~b}$ in which the smooth

461 hummocky facies is interpreted as the bedrock substrate that forms the Darwin basin. The model

462 in Figure $4 \mathrm{~b}$ is also supported by the rover-based observation that the sandstone beds around the

463 interior edge of the depression appear to dip toward the center of the basin, indicating that the

464 deposition of these beds was influenced by the geometry of a pre-existing depression.

465

466 4.2. Cooperstown

$467 \quad$ 4.2.1 Orbital Facies

468 The smooth dark, boulder hummocky, smooth hummocky, resistant cratered outcrop, and

469 bright outcrop orbital facies mapped at the Darwin area are also observed in HiRISE images of

470 the Cooperstown waypoint (Figure 8). The bright outcrop orbital facies mapped at Cooperstown

471 appears to be bluer in the HiRISE color image than that mapped at Darwin, perhaps indicating a

472 greater proportion of mafic sand cover on the outcrop (Figure 3). Two orbital facies not present

473 at Darwin were observed in the Cooperstown area: the bright striated outcrop and the bright

474 fractured outcrop orbital facies. The bright striated outcrop orbital facies occurs as a small

475 isolated outcrop in the lower right part of the mapping area and is characterized by its relative

476 brightness in the gray-scale HiRISE mosaic and a white to tan color in the HiRISE color mosaic

477 (Figure 9a). Most distinctive however, are the northeast-southwest trending lineations that occur

478 across the bright striated outcrop orbital facies exposure at approximately even meter-scale

479 spacing (Figure 9b). At Cooperstown, the bright fractured outcrop orbital facies is distinguished

480 from surrounding bright outcrop orbital facies by the presence of distinct meter-scale polygonal

481 fractures and a bright white-yellow color in the HiRISE color mosaic (Figure 2c and Figure 3). 
The bright outcrop orbital facies mapped in the northeastern portion of the Cooperstown

483 area forms a sub-circular outcrop shape in planform, possibly indicating a crater fill. However,

484 other occurrences of the bright outcrop orbital facies are interpreted to extend in the subsurface

485 throughout the mapping area as horizontal layers with the resistant cratered outcrop conformably

486 overlying the bright outcrop facies strata (Figure 8b). The smooth hummocky, smooth dark, and

487 boulder hummocky orbital facies are interpreted as unconsolidated surficial deposits overlying

488 the resistant cratered and bright outcrop facies for the same reasons discussed for these orbital

489 facies at the Darwin waypoint.

\section{$490 \quad$ 4.2.2 Rover Image-Based Geologic Mapping}

491 The Cooperstown M-100 mosaic shows an area dominated by sandstone outcrops of

492 variable texture, grain size, and bedding characteristics (Figures 5d-5e, 10a, 10c, and 11). The

493 foreground of the Cooperstown mosaic (Figure 10a, bottom left) includes an exposure of dark,

494 fine-grained sandstone containing centimeter-scale vugs (Figure 5e). The dark, vuggy sandstone

495 transitions into exposures of inter-bedded platy, cross-stratified sandstone and more thickly-

496 bedded sandstone (cm-scale beds) that occur on both the left and right sides of the mosaic

497 (Figure 5d,10c). This interval is overlain by sandstone with apparently massive texture (Figure

498 11). The massive sandstone is overlain by a distinct, erosion-resistant bed of pebbly sandstone

499 (Figure 11a and 11b). Several float accumulations occur in the Cooperstown area (i.e., Figure

500 5f), including a mound near the center of the mosaic separating the two inter-bedded platy and

501 bedded sandstone outcrops (Figure 10c). Float and intermittent sandstone outcrops dominate the 502 rest of the area visible in the mosaic.

503 The stratigraphic section observed near the Cooperstown contact science location shows

504 a basal interval of cross-stratified fine-grained sandstone overlain by nearly a meter of massive 
505 coarse-grained sandstone that exhibits a sharp inclined basal contact (Figures 11a and 15b).

506 Granule-sized clasts are present within the coarse sandstone, as are thin, platy lenses similar to

507 those observed at the Darwin outcrop. The massive coarse-grained sandstone is overlain by a

508 pebbly sandstone containing fine-grained, highly angular, and irregularly shaped clasts (Figure

509 11b).

\section{$510 \quad$ 4.2.3 Comparison between Orbital and Rover Image-Based Mapping}

511 The comparison of orbital facies and ground-based geology observations is illustrated in

512 Figure 10. The smooth dark orbital facies corresponds to some, but not all, of the areas mapped

513 as float in the rover mosaic. Other occurrences of float in the area were mapped in the orbital

514 images as resistant cratered outcrop, smooth hummocky, and bright outcrop orbital facies

515 (Figures 10b and 10c). The boulder hummocky orbital facies corresponds well with an

516 accumulation of dark float of a fine-grained lithology observed in the rover mosaic as expected

517 since the largest of the boulders are visible in HiRISE (Figures $2 \mathrm{c}$ and 3). The resistant cratered

518 outcrop orbital facies appears to correspond most directly with outcrops exposed on local

519 topographic highs but does not correspond uniquely to a lithology or surficial deposit. For

520 example, the outcrop of vuggy sandstone visible in the foreground of the Cooperstown rover

521 mosaic corresponds to an area mapped as resistant cratered outcrop orbital facies, as does the

522 resistant pebble sandstone bed and a mound of float located in the center of the mosaic field of

523 view (Figures 10b and 10c). Although the resistant cratered outcrop orbital facies corresponds to

524 a variety of bedrock lithologies observed from the rover perspective, the mapped boundaries of

525 this orbital facies do correspond consistently with contacts between sandstone lithologies that

526 show variable resistance to erosion. As at Darwin, the bright outcrop orbital facies at 
527 Cooperstown is well correlated with outcrops of apparently massive, bedded, and platy sandstone

528 viewed by the rover.

529 4.3. Kimberley

$530 \quad$ 4.3.1 Orbital Facies

531 Three orbital facies, the smooth hummocky outcrop, smooth boulder outcrop, and bright

532 bedded outcrop orbital facies, were mapped at the Kimberley waypoint in addition to orbital

533 facies discussed previously (Figure 12a). As at Darwin and Cooperstown, the smooth hummocky

534 orbital facies observed at Kimberley rarely forms scarps, appears smooth on a meter-scale, and

535 exhibits no sign of internal stratification. Therefore, it is interpreted as an unconsolidated

536 surficial deposit. However, there are small patches exposed within the smooth hummocky orbital

537 facies that exhibit variable surface texture, appear to shed small boulders, and in some

538 occurrences retain craters. These areas are more similar in brightness and color hue to the smooth

539 hummocky orbital facies rather than the bright outcrop orbital facies and do not exhibit scarps as

540 is common around exposures of the resistant cratered outcrop orbital facies. Therefore, these

541 areas are mapped as a new orbital facies, the smooth hummocky outcrop. The smooth boulder

542 outcrop orbital facies is distinguished by the presence of rounded hills that are uniform in tone

543 and color and appear generally smooth except for the accumulations of boulders found on the

544 sides of the hills (Figure $2 \mathrm{~d}$ and 3 ). The bright bedded outcrop orbital facies appears gray and tan

545 in the HiRISE color mosaic and is characterized by horizontal bedding planes visible in the

546 orbital images (Figure 3). This orbital facies lacks the textural diversity apparent in the bright

547 striated and bright fracture outcrop orbital facies. Although a small exposure of the bright

548 striated orbital facies was observed in the Cooperstown area, this orbital facies is more

549 extensively present in the Kimberley area (Figure 9c and 9d). From examining the HiRISE 
550 images alone, it is difficult to ascertain the origin of the striations that distinguish this orbital

551 facies. But at Kimberley, the striations are observed to be so linear within individual outcrop

552 exposures that several possibilities exist to explain the geometry of these features: (1) the

553 striations are defined by surface lineations rather than planes that extend into the subsurface, (2)

554 the striations are defined by planes (e.g., beds) having an inclination that is steep relative to

555 changes in outcrop topography, or (3) the striations are defined by three-dimensional curved

556 planes, but outcrop topography consistently counteracts the curvature of these planes. The first

557 two options are likely the most plausible, albeit indistinguishable from HiRISE images alone,

558 while the third option requires a more contrived set of circumstances and is therefore less likely.

559 The well-exposed and clearly defined outcrops visible in HiRISE at the Kimberley

560 waypoint enable an interpretation of the bright striated outcrop, bright bedded outcrop, and

561 smooth hummocky orbital facies as stratigraphic units that can be projected into the subsurface

562 with greater confidence than at the previous waypoints. The cross-section presented in Figure

$56312 \mathrm{~b}$ illustrates the interpreted relative age relationship between these orbital facies; the

564 stratigraphically lowest and hence oldest facies exposed in this area is the bright striated outcrop

565 orbital facies, which is overlain by the bright bedded outcrop and smooth hummocky orbital

566 facies. The topographic profile extracted across the bright striated outcrop orbital facies shows

567 that this facies exhibits up to 2 meters of relief over the area it is exposed at the surface,

568 suggesting an erosional contact between the bright striated outcrop and the overlying bright

569 bedded outcrop orbital facies. Buttes of the smooth boulder outcrop and the resistant cratered

570 orbital facies are interpreted to overlie the bright bedded outcrop facies, although the relative age

571 relationship between the smooth boulder and the resistant cratered orbital facies is unknown. The

572 smooth hummocky, boulder hummocky, and smooth dark orbital facies are best interpreted as 
573 unconsolidated surficial deposits that overlie eroded outcrops of the bright bedded, striated, and

574 fractured outcrop orbital facies, as well as the resistant cratered and smooth boulder outcrop

575 orbital facies. The stratigraphic relationship between the smooth hummocky outcrop orbital

576 facies and the other facies mapped in the area is difficult to determine from orbital mapping

577 alone. However, the mottled texture and brighter tone of the smooth hummocky outcrop facies

578 compared to the surrounding smooth hummocky facies suggest that it may represent bedrock

579 unlike the other "hummocky" facies which are interpreted as unconsolidated mantle deposits.

\section{$580 \quad$ 4.3.2 Rover Image-Based Geologic Mapping}

581 The Kimberley M-100 mosaic covers an outcrop of south-dipping coarse-grained

582 sandstone beds with variable resistance to erosion (Figures 5g. 13. 14c). Coarse sandstone beds

583 containing granule-sized clasts underlie the south-dipping beds (Figure 14d). Fine-grained

584 sandstones showing no preferential southward dip overlie the south-dipping sandstone beds

585 (Figure 5h, 14a, and 14b). The three hills visible at the Kimberley outcrop are primarily covered

586 in float (Figure 5I, 13c), although each hillside exhibits apparently massive interstratified

587 sandstone. The terrain surrounding the Kimberley outcrop is largely covered in unconsolidated

588 accumulations of float (Figure 13c).

589 The stratigraphic column shown in Figure 15 was constructed from observations made at

590 and nearby the location of the Windjana drill site at the southeastern edge of the Kimberley

591 outcrop (Figure 14). Here, coarse granule sandstone (Figure 14d) underlies the sandstone beds

592 that transition from primarily horizontal to south-dipping orientations (Figure 14c). The south-

593 dipping strata are overlain by cross-stratified very fine-grained sandstone beds bounded at the

594 base by a sharp, undulatory contact (Figure 14a and 14b). The cross-stratified sandstone is

595 overlain by sandstones of a grain size that is not resolvable in the Mastcam images and was not 
596 observed with MAHLI, but appears to be relatively fine-grained (Figure 14a). Coarse-grained,

597 possibly south-dipping beds are observed within this interval, but the presence of float and cover

598 make it difficult to identify sedimentary structures or bedding within this interval. An

599 accumulation of dark float occurs at the top of the hill informally named Mount Remarkable..

600 4.3.3. Comparison between Orbiter and Rover Image-Based Mapping

601 The comparison of orbiter versus rover image-based observations shown in Figure 13

602 reveals a relatively good correlation between orbital facies contacts and geology contacts

603 observed in the Kimberley Mastcam mosaic. Due to the well-exposed outcrop at the Kimberley

604 waypoint, there is a nearly perfect correlation between the mapped distribution of bright striated

605 outcrop orbital facies and the south-dipping resistant and recessive sandstones mapped in the

606 rover mosaic (Figures 13b and 13c). Using rover image-based observations of the bright striated

607 outcrop orbital facies, the three possible origins of the striations described in the previous section

608 can be re-evaluated. The presence of south-dipping sandstone beds of variable resistance in areas

609 mapped as bright striated outcrop orbital facies indicate that the striations cannot be completely

610 explained as surface lineations (option 1), but are due in large part to the intersection of inclined

611 bedding planes with the modern day erosional outcrop topography (option 2). There is no

612 evidence from ground-based rover observations that the bedding planes are curved, so option 3

613 can be eliminated.

614 Areas mapped as float in the rover mosaic correspond to the smooth hummocky orbital

615 facies, and areas containing a higher proportion of sand to float are generally mapped in the

616 HIRISE images as smooth dark orbital facies. The bright bedded outcrop orbital facies

617 corresponds well with flat-lying platy sandstone beds mapped in the Mastcam mosaic, and the

618 contact between these platy sandstones and underlying south-dipping sandstone beds is identified 
619 with high fidelity in both the orbital map and rover mosaic (Figure 12a and 12c). The three hills

620 present at the Kimberley waypoint were mapped in HiRISE images as smooth boulder outcrop

621 orbital facies, which corresponds to accumulations of fine-grained float and intermittent

622 exposures of sandstone on the slopes of the hills. The smooth appearance of these hills in orbital

623 images is likely due to accumulations of sand and float on the hilltops.

625 5. Discussion

626 The comparison between orbital facies mapping and rover image-based geologic

627 mapping at the Darwin, Cooperstown, and Kimberley waypoints illustrates several important

628 points about the utility and validity of orbiter image-based geologic interpretations. Orbital facies

629 mapping is useful for distinguishing in-place bedrock from unconsolidated deposits, and can be

630 used to identify geologically significant contacts if outcrop exposure is good and adjacent facies

631 exhibit differences in brightness, surface texture, or weathering characteristics such as resistance

632 to erosion. This is particularly important since datasets such as THEMIS-derived thermal inertia

633 (100 m/pixel) and CRISM ( $\sim 18 \mathrm{~m} /$ pixel), which can also provide information about physical and

634 compositional differences on the surface, have resolutions too coarse to allow meaningful

635 distinction between orbital facies mapped at the scale employed in this study. At all three

636 waypoints, the bright outcrop orbital facies, including the bright striated, bright bedded, and

637 bright fractured outcrop orbital facies, were correctly identified during HiRISE mapping as in-

638 place, lithified outcrop. The resistant cratered outcrop facies was also correctly identified as

639 bedrock at Cooperstown and Kimberley. The smooth dark, boulder hummocky, and smooth

640 hummocky orbital facies were correctly identified from orbital images as largely unconsolidated

641 surficial deposits. The exception is the smooth hummocky orbital facies mapped at Darwin, 
642 where intermittent exposures of sandstone and conglomerate bedrock could not be resolved from

643 orbital images. The ability to distinguish between lithified rock outcrop and unconsolidated

644 surficial deposits is important and particularly useful for planning rover science investigations

645 and performing traverse and mobility assessment. In-place rock outcrops rather than

646 unconsolidated deposits are often the desired science target for investigations of depositional

647 processes, paleoenvironment, and geochemistry of ancient sedimentary rocks. Conversely,

648 terrain consisting of unconsolidated surficial deposits may be favored over in-place outcrop

649 when planning traverses that minimize wheel damage and hazard to the roving vehicle [Yingst et

650 al., 2014].

651 Orbital facies maps can also be useful for recognizing distinct contacts between bedrock

652 units, particularly when accompanied by a clear topographic scarp or mappable differences in

653 brightness, color, or surface texture. The ability to recognize significant geologic contacts from

654 orbiter image datasets is particularly important for making strategic decisions during mission

655 surface operations that determine where a rover is sent to address hypotheses about the geologic

656 nature of the site. Orbital geologic interpretations initially guided the MSL team in its decision to

657 drive the Curiosity rover to Yellowknife Bay [Grotzinger et al., 2014; Palucis et al., 2014], and

658 several examples from this study illustrate the utility of orbital facies mapping for identifying

659 geologically significant contacts. At the Cooperstown waypoint, the mapped contact between the

660 resistant cratered outcrop and the bright outcrop orbital facies in the vicinity of the contact

661 science location represents a sharp transition between the massive and platy-bedded fine

662 sandstone beds and the resistant pebbly sandstone. At Kimberley, where outcrop is well-exposed

663 and orbital facies are easily distinguished in HiRISE images, the orbital map interpretations

664 provided sufficient information to identify the contact between south-dipping coarse sandstone 
665 beds and the overlying flat-lying platy sandstones (Figure 12a and Figure 12c), a stratigraphic

666 relationship that was critical for determining the origin of the enigmatic striations observed in

667 HiRISE images (Figure 9c and 9d).

668 There are also ways in which orbital map interpretations are limited, particularly when

669 used alone without corresponding datasets acquired on the ground. Differences in relative

670 brightness, color, or textural characteristics observed in orbital image datasets may indeed be

671 suggestive of inherent differences in the material properties of bedrock units, but these orbital

672 characteristics can be non-unique and heavily biased by unconsolidated materials exposed

673 immediately at the surface. For example, the presence and distribution of thin, discontinuous

674 surficial deposits of float, sand, and dust may result in the distinction of multiple orbital facies

675 within the same geological unit due to changes in color and brightness caused only by these

676 mantling materials. The two alternate cross-section interpretations presented for the Darwin

677 waypoint illustrate this point. In the first cross-section (Figure 4b), the smooth hummocky orbital

678 facies observed at the surface is interpreted as a distinct and important stratigraphic unit of at

679 least several meters thickness that forms the substrate of the basin in which younger facies were

680 deposited. In contrast, in the second cross-section interpretation (Figure 4c) the smooth

681 hummocky orbital facies is interpreted as a relatively thin mantle deposit that is obscuring more

682 extensive underlying exposures of bright outcrop and resistant cratered outcrop orbital facies.

683 The two interpretations have very different implications for the timing and relative age

684 relationship of the outcrops and deposits observed from orbital datasets and on the ground as

685 well as the timing of basin formation, yet it is challenging to distinguish between the two

686 hypotheses using the orbital image data. Rover image-based observations reveal that the smooth

687 hummocky facies is in-part composed of in-place bedrock and that deposition of sandstone beds 
688 within the Darwin depression appears to have been influenced by the geometry of pre-existing 689 depression; both observations are consistent with and best explained by the stratigraphic model 690 presented in Figure 4b. This example supports the rationale for sending rovers to the surface of 691 planetary bodies as it is difficult to ascertain the degree of heterogeneity at outcrop scale from 692 orbit, and to interpret the significance of that heterogeneity.

693 As another example of the non-uniqueness of orbital facies interpretations, consider two 694 areas, Darwin and Cooperstown, that exhibit similar remote sensing properties. At the Darwin 695 waypoint, the resistant cratered outcrop orbital facies corresponds to accumulations of 696 unconsolidated float blocks. In contrast, the resistant cratered outcrop orbital facies at 697 Cooperstown corresponds to a variety of in-place, lithified sandstone outcrops. Some of the 698 outcrops mapped as resistant cratered orbital facies at Cooperstown were fine-grained and 699 vuggy, whereas others were coarse-grained and contained pebble-size clasts, likely representing 700 very different depositional conditions and/or processes. Based solely on orbital mapping, these 701 resistant cratered outcrop facies occurrences could be interpreted and correlated as co-eval

702 deposits of a similar origin, but rover-based observations show that such a correlation would not 703 be valid. In addition, the bright outcrop orbital facies mapped at all three Curiosity waypoints 704 may suggest that a time-rock correlation of these orbital facies could be appropriate. However, a 705 closer examination of the bedrock outcrop with rover images at each waypoint (Figure 15), calls 706 into question the validity of such a correlation. At Darwin, the bright outcrop orbital facies 707 corresponds to an outcrop of coarse sandstones and pebble conglomerates, whereas the bright 708 outcrop mapped at Cooperstown corresponds to fine-grained platy-bedded and massive 709 sandstones. While a general regional correlation between these two locations may still be 710 possible, the rover data reveal no clear rationale for a geologic correlation of the contact between 
711 the bright outcrop and overlying resistant cratered outcrop orbital facies mapped at Darwin with

712 that same orbital facies contact mapped at Cooperstown.

713 The orbital and ground-based comparisons presented in this study also illustrate the

714 difficulty in making process-based interpretations from orbital mapping alone, particularly in

715 areas like Bradbury Rise in Gale crater where present-day topography and geomorphology

716 provide few indications of past depositional process or paleoenvironment. For comparison, there

717 are some locations on the surface of Mars where depositional interpretations are possible based

718 almost solely on orbital observations, as is the case for inverted relief features such as channels

719 or preserved fans or deltas, volcanic constructs such as lava flow lobes, or impact ejecta deposits.

720 The Peace Vallis fan in Gale crater is an example of such a deposit. The present-day topography

721 of this feature enables its identification as an alluvial fan, for which calculations of total volume

722 and runoff can be made [Palucis et al., 2014]. The distribution of inverted channel features and

723 measurements of present-day fan slope also allows an evaluation of the relative importance of

724 various depositional processes contributing to fan formation, particularly the role of distributary

725 channel formation versus sheet flow, debris flow, and mud flow deposition throughout the fan

726 [Palucis et al., 2014]. Furthermore, the location of Yellowknife Bay at the distal end of the Peace

727 Vallis fan led the MSL team to hypothesize that fine-grained sediments representing deposition

728 in a lacustrine setting might be found there, a hypothesis that was "field checked" and proven

729 correct by observations from the Curiosity rover [Grotzinger et al., 2014; Palucis et al., 2014].

730 In contrast, Bradbury Rise lacks diagnostic paleogeomophic features such as those characterizing

731 the Peace Vallis fan and unlike Yellowknife Bay, Bradbury Rise shows no clear temporal or

732 spatial relationship with the Peace Vallis fan. Therefore, distinguishing a process-based

733 sedimentary origin for the three waypoints examined in this study from orbital image data alone 
734 is admittedly challenging. In these cases, rover image-based observations of lithology, grain

735 size, and texture are essential for interpreting depositional hypotheses.

736 As a consequence of the various limitations described above, it is common practice for

737 orbital stratigraphic interpretations to show simple "layer cake" stratigraphic models in which

738 orbital facies are interpreted as stratal units of relatively constant thickness, horizontal

739 deposition, and lateral continuity at least at the scale of the drafted cross-section. This is usually

740 the simplest model to interpret the data. The cross-sections presented for each waypoints in

741 Figures 4, 8, and 12 are modeled by this "layer cake" geometry, as is the regional schematic

742 cross-section of Bradbury Rise incorporating all three waypoints shown in Figure 16a. Because

743 the geometry of subsurface units in these examples provides no indication of a process-based

744 depositional interpretation of the stratigraphic units, more complex stratigraphic models, though

745 plausible, would likely be an over-interpretation of the available data and thus speculative.

746 Although some "layer cake" models may be valid representations of the subsurface geology, in

747 situ observations of the bedrock outcrop and surficial deposits present at the three waypoints in

748 Gale crater suggest that a more appropriate model for the subsurface of Aeolis Palus is that

749 shown in the schematic in Figure 16b. In this model, the fundamental principles of stratigraphy

750 still hold, but lithologic units exposed at the surface are mapped and interpreted in the context of

751 the fluvial depositional system suggested for Bradbury Rise by the in situ analysis of Williams et

752 al. [2013], Grotzinger et al. [2014], and Vasavada et al. [2014]. Such a model for the subsurface

753 stratigraphy is likely closer to reality for fluvial depositional systems than the layer cake model

754 presented in Figure 16a, but its construction was only suggested from ground-based

755 interpretations of the outcrops exposed throughout Aeolis Palus. 


\section{Implications for mapping future landing sites on Mars}

High-resolution orbital images have been incredibly important for increasing recent

759 understanding of the geological diversity of the martian surface and have made a positive impact

760 on surface mission landing site selection and surface operations. But this study shows that even

$76125 \mathrm{~cm} /$ pixel HiRISE images mapped at a 1:500 scale will provide limited to no information

762 about the small-scale textural characteristics of an outcrop, including grain size, lithology, or

763 internal structures (e.g., bedforms and fine-scale bedding characteristics), that are critical for

764 making depositional interpretations even as fundamental as sedimentary versus volcanic. The

765 vertical viewing geometry of orbital imaging systems can also limit the amount of geologically

766 significant information gleaned from outcrop exposures observed in orbital data, particularly

767 because three-dimensional outcrop exposures are difficult to observe in orbital data. Yet orbital

768 images provide a breadth of surface coverage and the local-to-regional context for detailed rover

769 observations that the limited visual range and horizontal viewing geometry of a ground-based

770 rover cannot provide, highlighting how complementary the combined approach of orbiter and

771 rover-image based analysis can be.

772 Developing more complex and detailed process-based models for the depositional history

773 of martian landing sites through the integration of detailed orbital facies mapping and analysis of

774 rover images is critical for making better-informed predictions of where Curiosity or future

775 rovers might concentrate effort and resources to find preserved evidence of past habitable

776 environments, organic matter, or other biosignatures. Ground-based rovers are needed to

777 measure small-scale textural characteristics of rock outcrops, such as grain size, lithology,

778 sedimentary structures, bedding style, and allow the exploration of three-dimensional outcrop

779 exposures that are essential for paleoenvironmental reconstructions. Detailed orbital mapping of 
780 high-resolution image datasets like that carried out in this study aids in the planning and

781 execution or rover measurements on daily or monthly operational timescales and provides

782 critical context for these measurements at a finer-scale than that typically employed in regional

783 or global orbital map investigations.

784 As critical as the integration of orbiter and rover data is for understanding the past

785 depositional processes and paleoenvironments on the surface of Mars, the reality is that rover

786 and landed missions to Mars are rare and the majority of the planet can only be studied with

787 orbital data sets. Although it may not be practical to map large areas of the martian surface at the

788 1:500 scale (or finer) employed for the waypoint study areas here, for locations on Mars

789 considered of interest for future rover or even human missions, the analysis of high resolution

790 orbital image datasets through fine-scale orbiter image-based mapping efforts are important for

791 mission planning purposes as well as predicting in advance the diversity of rock outcrops and

792 deposits that will be encountered.

793 This study highlighted some of the considerable challenges that persist with geologic

794 interpretations of the highest resolution orbital images currently available of the martian surface,

795 but future airborne or orbital imaging systems designed to image at even higher resolutions could

796 help resolve the limitations of existing orbital geologic interpretations. Imaging at the $\sim 1-5$

$797 \mathrm{~cm} /$ pixel scale would afford the ability to recognize finer distinctions in outcrop texture that

798 could significantly aid in the depositional interpretation of orbital facies and the recognition of

799 locally and regionally significant geologic contacts.

800

801

802

\section{Conclusions}


804 during its traverse from Yellowknife Bay to the base of Aeolis Palus. This study presents

805 detailed orbital facies maps for each waypoint based on HiRISE images and provides a

806 comparison between orbital facies mapping and geologic mapping based on images from the

807 Curiosity rover Mastcam M-100 and MAHLI cameras. The results of the orbiter and rover-based 808 comparison are as follows:

809 (1) Orbital facies mapping is generally useful for distinguishing between in-place bedrock $810 \quad$ outcrop and unconsolidated surficial deposits.

811 (2) Orbital facies mapping can be used to identify distinct geologic contacts if outcrop 812 exposure is good and adjacent facies exhibit differences in brightness, color hue, surface 813 texture, or resistance to erosion.

814 (3) The remote sensing properties used to define orbital facies and the geologic

815 interpretations that result from these observations can be non-unique and biased by a 816 mapper's interpretation of how distinct those properties are. This leads to challenges in 817 accurately correlating spatially distinct orbital facies.

818 (4) Process-based interpretations based on orbital image observations alone should be made 819 cautiously for landscapes such as Bradbury Rise, which lack clear paleogeomorphic 820 landforms or topography indicative of a particular depositional process.

821 (5) Stratigraphic architecture interpreted from orbital maps is often represented as "layer 822 cake" models, but these models are inconsistent with Curiosity rover observations of the 823 ancient sedimentary environments explored in Gale crater. Integration of orbiter and 824 rover image-based observations is needed to construct more sophisticated stratigraphic or 825 depositional models. 
(6) Fine-scale orbital mapping of future candidate landing sites, actual landing sites, and field investigation traverse paths like that presented in this study, integrated with rover imagebased observations enables better-informed predictions of where ground-based rover missions might concentrate effort and resources to find preserved evidence of past habitable environments, organic matter, or other biosignatures.

\section{Acknowledgments}

833 This research was carried out at the Jet Propulsion Laboratory, California Institute of

834 Technology, under a contract with the National Aeronautics and Space Administration. Thanks

835 to Mike Malin for providing the processed Mastcam mosaics used in this study. The authors

836 would like to acknowledge the scientists and engineers of the MSL and MRO HiRISE missions,

837 without whom the data and analysis presented in this paper would not have been possible. We

838 also thank Brad Thomson and an anonymous reviewer for providing helpful feedback that

839 improved this manuscript.

840

\section{$841 \quad$ References}

842 Anderson, R. B. and J. F. Bell III (2010), Geologic mapping and characterization of Gale Crater and implications for its potential as a Mars Science Laboratory landing site, Mars, 5, 76128, doi:10.1555/mars.2010.0004. integrated software for imagers and spectrometers, Lunar and Planetary Science Conference, 35, 2039.

Arvidson, R. E. et al. (2006), Nature and origin of the hematite-bearing plains of Terra Meridiani based on analyses of orbital and Mars Exploration rover data sets, J. Geophys. Res., 111, E12S08, doi:10.1029/2006JE002728.

Arvidson, R. E., et al. (2008), Mars Exploration Program 2007 Phoenix landing site selection and characteristics, J. Geophys. Res., 113(E00A03), doi:10.1029/2007JE003021.

Arvidson, R. E., et al. (2014), Terrain physical properties derived from orbital data and the first 360 sols of Mars Science Laboratory Curiosity rover observations in Gale Crater, JGRPlanets, 119, 1322-1344, doi:10.1002/2013JE004605. 
Arvidson, R. E. et al. (2015). Mars Reconnaissance Orbiter and Opportunity observations of Burns Formation and underlying strata: Crater-hopping at Meridiani Planum, J. Geophys. Res. - Planets, 120, doi:10.1002/2014JE004686.

Binder, A.B., Arvidson, R.E., Guinness, E.A., Jones, K.L., Morris, E.C., Mutch, T.A., Pieri, D.C. and Sagan, C. (1977). The geology of the Viking lander 1 site. Journal of Geophysical Research, 82, doi: 10.1029/JB082i028p04439.

Cabrol, N. A., E. A. Grin, H. E. Newsom, R. Landheim, C. P. McKay (1999), Hydrogeologic Evolution of Gale Crater and Its Relevance to the Exobiological Exploration of Mars, Icarus, 139, 235-245.

Calef, F. J., III, W. E. Dietrich, L. Edgar, J. Farmer, A. Fraeman, J. Grotzinger, M. C. Palucis, T. Parker, M. Rice, S. Rowland, K. M. Stack, D. Sumner, J. Williams, and the MSL Science Team (2013), Geologic Mapping of the Mars Science Laboratory Landing Ellipse, Lunar and Planetary Science Conference, 44, 2511.

Crumpler, L. S., R. A. Craddock, and J. C. Aubele (2001), Geologic map of the MTM 25047 and 20047 quadrangles, central Chryse Planitia/Viking 1 Lander site, Mars, IMAP 2693, U.

S. Department of the Interior, U.S. Geological Survey.

Crumpler, L. S., et al. (2011), Field reconnaissance geologic mapping of the Columbia Hills, Mars, based on Mars Exploration Spirit and MRO HiRISE observations, JGR-Planets, 116(E00F24), doi:10.1029/2010JE003749.

Crumpler, L. S. et al. (2015), Context of ancient aqueous environments on Mars from in situ geologic mapping at Endeavor Crater, J. Geophys. Res., 120(3), doi:10.1002/2014JE004699.

Edmundson, K. L., D. A. Cook, O. H. Thomas, B. A. Archinal, and R. L. Kirk (2012), JIGSAW: The ISIS3 Bundle Adjustment for Extraterrestrial Photogrammetry, ISPRS Ann. Photogramm. Remote Sens. Spatial Inf. Sci., I-4, 203-208, doi:10.5194/isprsannals-I-4203-2012.

Edwards, C. S., K. J. Nowicki, P. R. Christensen, J. Hill, N. Gorelick, and K. Murray (2011), Mosaicking of global planetary image datasets: 1 . Techniques and data processing for Thermal Emission Imaging System (THEMIS) multi-spectral data, J. Geophys. Res., 116(E10), E10008, doi: doi:10.1029/2010JE003755.

Fergason, R. L., P. R. Christensen, M. P. Golombek, T. J. Parker (2012), Surface Properties of the Mars Science Laboratory Candidate Landing Sites: Characterization from Orbit and Predictions, Space Sci Rev, 170, 739-773, doi:10.1007/s11214-012-9891-3.

Golombek, M. P. et al. (2003), Selection of the Mars Exploration Rover landing sites, JGR, 108(E12), 8072, doi:10.1029/2003JE002074.

Golombek M. P. et al. (2005), Assessment of Mars Exploration Rover landing site predictions, Nature, 436, 44-48, doi:10.1038/nature03600.

Golombek, M. P. et al. (2006), Geology of the Gusev cratered plains from the Spirit rover transverse, J. Geophys. Res., 11(E02S07), doi:10.1029/2005JE002503.

Golombek, M. P. et al. (2008), Size-frequency distributions of rocks on the northern plains of Mars with special reference to Phoenix landing surfaces, J. Geophys. Res., 113(E00A09), doi:10.1029/2007JE003065.

Golombek, M. P. et al. (2012), Selection of the Mars Science Laboratory Landing Site, Space Sci Rev, 170, 641-737, doi:10.1007/s11214-012-9916-y. 
Greeley, R. and J. E. Guest (1987), Geologic map of the eastern equatorial region of Mars: U.S. Geological Survey Miscellaneous Investigations Series Map I-1802-B, scale 1:15,000,000, U.S. Department of the Interior, U.S. Geological Survey.

Grotzinger, J. P. and R. E. Milliken (2012), The sedimentary rock record of Mars: Distribution, origins, and global stratigraphy, in Sedimentary Geology of Mars, SEPM Special Publication No. 102, edited by J. P. Grotzinger and R. E. Milliken, pp. 1-48, SEPM, Tulsa, O.K.

Grotzinger, J. P. et al. (2012), Mars Science Laboratory Mission and Science Investigation, Space Sci. Rev., 170, 5-55, doi:10.1007/s11214-012-9892-2.

Grotzinger J. P., et al. (2014), A Habitable Fluvio-Lacustrine Environment at Yellowknife Bay, Gale Crater, Mars, Science, 343, no.6169, doi:10.1126/science.1242777.

Grotiznger, J. P. et al. (2015), Deposition, exhumation, and paleoclimate of an ancient lake deposit, Gale crater, Mars, Science, 350, no. 6257, doi:10.1126/science.aac7575.

Hansen, V. L. (2000), Geologic mapping of tectonic planets, Earth and Planet. Sci. Lett., 176, 527-542.

Haskins et al. (1998), A Geomorphic Classification System, Version 1.4, Washington D.C., U.S. Department of Agriculture Forest Service, $110 \mathrm{p}$.

Jacob, S. R., S. Rowland, F. J. Calef III, K. M. Stack, and the MSL Team (2014), Characteristics and origin of a cratered unit near the MSL Bradbury landing site (Gale Crater, Mars) based on analyses of surface data and orbital imagery, Lunar and Planetary Science Conference, 45, 1395.

Jakosky, B.M. and Christensen, P.R. (1986). Global duricrust on Mars: Analysis of remotesensing data. Journal of Geophysical Research 91, doi: 10.1029/JB091iB03p03547.

LeDeit, L., E. Hauber, F. Fueten, M. Pondrelli, A. Pio Rossi, and R. Jaumann, Sequence of infilling events in Gale Crater, Mars: Results from morphology, stratigraphy, and mineralogy, JGR-Planets, 118, 2439-2473, doi:10.1002/2012JE004322.

Kirk, R. L., et al. (2008), Ultrahigh resolution topographic mapping of Mars with MRO HiRISE stereo images: Meter-scale slopes of candidate Phoenix landing sites, J. Geophys. Res., 113(E3), E00A24, doi:10.1029/2007JE003000.

Komatsu, G. and V. R. Baker (1997). Paleohydrology and flood geomorphology of Ares Vallis. Journal of Geophysical Research, 102. doi: 10.1029/96JE02564.

Maki, J. et al (2012). The Mars Science Laboratory Engineering Cameras, Space Sci. Rev., 170, 77-93, doi:10.1007/s11214-012-9882-4.

Milliken, R. E., J. P. Grotzinger, and B. J. Thomson (2010), Paleoclimate of Mars as captured by the stratigraphic record in Gale Crater, Geophys. Res. Lett., 37(L04201), doi:10.1029/2009GL041870.

Mutch, T. A., et al. (1977). The geology of the Viking Lander 2 site, J. Geophys. Res., 82(28), 4452-4467, doi:10.1029/JS082i028p04452.

Okubo, C. H. (2014). Bedrock geologic and structural map through the western Candor Colles region of Mars: U.S. Geological Survey Scientific Investigations Map 3309, pamphlet 8 p., scale 1:18,000, doi:10.3133/sim3309.

Palucis, M. C. et al (2014). The origin and evolution of the Peace Vallis fan system that drains to the Curiosity landing area, Gale Crater, Mars, J. Geophys. Res.- Planets, 119, 705-728, doi:10.1002/2013JE004583.

Pelkey, S. M., et al. (2004). Surficial properties in Gale Crater, Mars, from Mars Odyssey THEMIS data, Icarus, 167, 244-270, doi:10.1016/j.icarus.2003.09.013. 
Rice, J. W. and Edgett, K. S. (1997). Catastrophic flood sediments in Chryse Basin, Mars, and Quincy Basin, Washington: Application of sandar facies model. Journal of Geophysical Research 10,: doi: 10.1029/96JE02824.

Rice, M. S., J. F. Bell III, S. Gupta, N. H. Warner, K. Goddard, and R. B. Anderson (2013a), A detailed geologic characterization of Eberswalde crater, Mars, Mars, 8, 15-57, doi:10.1555/mars.2013.0002.

Rice, M. S., J. M. Williams, F. Calef, R. B. Anderson, L. Edgar, K. Stack, D. Y. Sumner, H. E. Newsom, J. P. Grotzinger, P. King (2013b), Detailed geologic mapping along the Mars Science Laboratory (MSL) Curiosity traverse path from Glenelg to Mount Sharp, Lunar and Planetary Science Conference, 44, 2892.

Scott, D. H. and M. H. Carr (1978), Geologic map of Mars: U.S. Geological Survey Mscellaneous Investigations Series Map I-1083, scale 1:25,000,000, U.S. Department of the Interior, U.S. Geological Survey.

Scott, D. H. and K. L. Tanaka (1986), Geologic map of the western equatorial region of Mars: U.S. Geological Survey Miscellaneous Investigations Series Map I-1802-A, scale 1:15,000,000, U.S. Department of the Interior, U.S. Geological Survey.

Seelos, K. D. et al. (2008), Geomorphologic and mineralogic characterization of the northern plains of Mars at the Phoenix Mission candidate landing sites, J. Geophys. Res., 113(E00A3), doi:10.1029/2008JE003088.

Sharp, R. P., and M. C. Malin (1984), Surface geology from Viking landers on Mars: A second look, Geological Society of America Bulletin, 95, 1398-1412, doi:10.1130/0016-7606(1984)95<1398:SGFVLO >2.0.CO;2.

Smith, P. H. et al. (1997), Results from the Mars Pathfinder Camera, Science, 278(5344), 17581765, doi:10.1126/science.278.5344.1758.

Sumner, D. S. et al. (2013). Preliminary Geological Map of the Peace Vallis Fan Integrated with In Situ Mosaics From the Curiosity Rover, Gale Crater, Mars, Lunar and Planetary Science Conference, 44, 1699.

Sun, V. Z. and R. E. Milliken (2014). The geology and mineralogy of Ritchey crater, Mars: Evidence for post-Noachian clay formation, J. Geophys. Res. Planets, 119, 810-836, doi:10.1002/2013JE004602.

Tanaka, K. L. and D. H. Scott (1987), Geologic map of the polar regions of Mars, Geologic Investigations Series Map I-1802-C, scale 1:15,000,000, U.S. Department of the Interior, U.S. Geological Survey.

Tanaka, K. L., J. A. Skinner, Jr., L. S. Crumpler, and J. M. Dohm (2009). Assessment of planetary geologic mapping techniques for Mars using terrestrial analogues: The SP Mountain area of the San Francisco Volcanic Field, Arizona, Planetary and Space Science, 57, 510-532, doi:10.1016/j.pss.2008.06.012.

Tanaka, K. L., J. A. Skinner, Jr., J. M. Dohm, R. P. Irwin, III, E. J. Kolb, C. M. Fortezzo, T. Platz, G. G. Michael, and T. M. Hare (2014), Geologic Map of Mars, Scientific Investigations Map 3292, U.S. Department of the Interior, U.S. Geological Survey. Thomson, B. J. and P. H. Schultz (2007), The geology of the Viking Lander 2 site revisited, Icarus, 191, 505-523, doi:10.1016/j.icarus.2007.05.011.

Thomson, B. J., N. T. Bridges, R. E. Milliken, A. Baldridge, S. J. Hook, J. K. Crowley, G. M. Marion, C. R. de Souza Filho, A. J. Brown, C. M. Weitz (2011), Constraints on the origin and evolution of the layered mound in Gale Crater, Mars using Mars Reconnaissance Orbiter Data, Icarus(214), 413-432, doi:10.1016/j.icarus.2011.05.002. 
992

993

994

995

996

997

998

999

1000

1001

1002

1003

1004

1005

1006

1007

1008

1009

1010

1011

1012

Vasavada, A. R., J. P. Grotzinger, R. E. Arvidson, F. J. Calef, J. A. Crisp, S. Gupta, J. Hurowitz, N. Mangold, S. Maurice, M. E. Schmidt, R. C. Wiens, R. M. E. Williams, and R. A. Yingst (2014), Overview of the Mars Science Laboratory mission: Bradbury Landing to Yellowknife Bay and beyond, JGR-Planets, 119, 1134-1161, doi:10.1002/2014JE004622.

Wilhelms, D. E. (1990), Geologic mapping, in Planetary Mapping, edited by R. G. Greeley and R. M. Batson, Cambridge Planetary Science Series 6, pp. 208-260, Cambridge University Press, Cambridge.

Williams, R. M. E., et al. (2013), Martian Fluvial Conglomerates at Gale Crater, Science, 340(6136), 1068-1072, doi:10.1126/science.1237317.

Wiseman, S. M., et al. (2010), Spectral and stratigraphic mapping of hydrated sulfate and phyllosilicate-bearing deposits in northern Sinus Meridiani, Mars, Journal of Geophysical Research: Planets, 115(E7), E00D18, doi:10.1029/2009JE003354.

Wray, J. J., E. Z. Noe Dobrea, R. E. Arvidson, S. M. Wiseman, S. W. Squyres, A. S. McEwen, J. F. Mustard, and S. L. Murchie (2009), Phyllosilicates and sulfates at Endeavor Crater, Meridiani Planum, Mars, Geophys. Res. Lett., 36(L21201), doi:10.1029/2009GL040734.

Yingst, R. A. et al. (2014). Terrain Assessment in Gale Crater from Sol 0-500 Using Orbital Thermal Inertia and In Situ Visible Data, Geological Society of America Annual Meeting, Vancouver, B. C., Paper No. 202-8.

Zimbelman, J. R. and S. P. Scheidt (2012). Hesperian Age for Western Medusae Fossae Formation, Mars, Science, 336(6089), 1683, doi:10.1126/science.1221094. 


\section{Tables}

\section{Table 1. Curiosity rover waypoints during the Bradbury Rise traverse}

\begin{tabular}{cccc}
\hline Waypoint & $\begin{array}{c}\text { Arrival } \\
\text { Sol }\end{array}$ & $\begin{array}{c}\text { Departure } \\
\text { Sol }\end{array}$ & Curiosity Rover Geology Investigation \\
\hline Darwin & 392 & 401 & $\begin{array}{c}\text { Remote sensing (Mastcam and Chemcam) and Contact Science (APXS } \\
\text { and MAHLI) }\end{array}$ \\
Cooperstown & 441 & 443 & $\begin{array}{c}\text { Remote sensing (Mastcam and Chemcam) and Contact Science (APXS } \\
\text { and MAHLI) }\end{array}$ \\
Kimberley & 574 & 631 & $\begin{array}{c}\text { Remote sensing (Mastcam and Chemcam), Contact Science (APXS and } \\
\text { MAHLI), Dust Removal Tool (DRT), Drill, CheMin, SAM }\end{array}$ \\
\hline
\end{tabular}




\section{Figures}

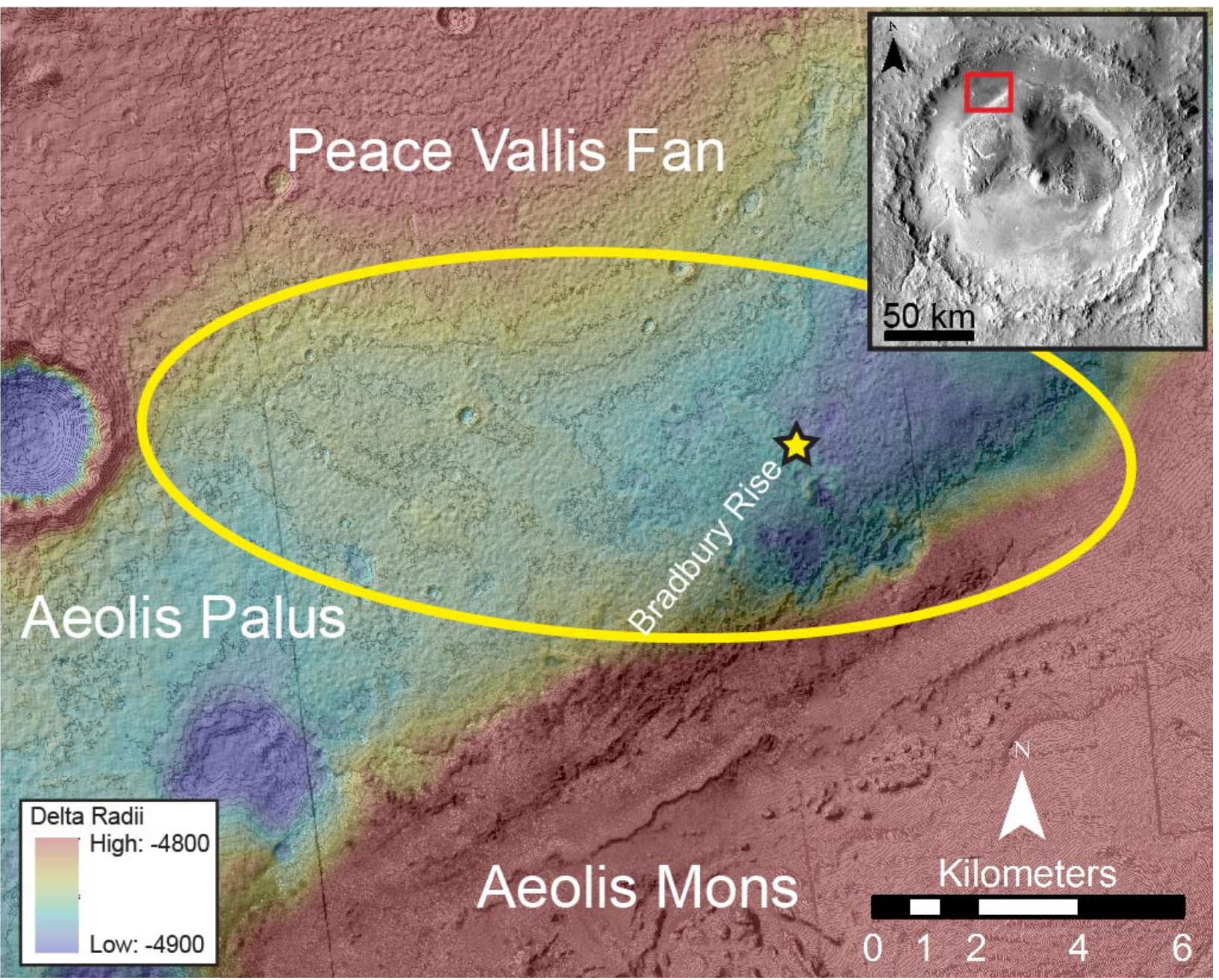

1017 Figure 1. MSL Curiosity landing ellipse (yellow ellipse), Bradbury Landing, Curiosity’s landing

1018 site (yellow star), and the location of Bradbury Rise annotated on a shaded relief HiRISE stereo

1019 image-derived topographic map of the Peace Vallis Fan, Aeolis Palus, and Aeolis Mons.

1020 Contours represent 10 meter intervals. Inset figure shows Gale crater in THEMIS Day IR. 


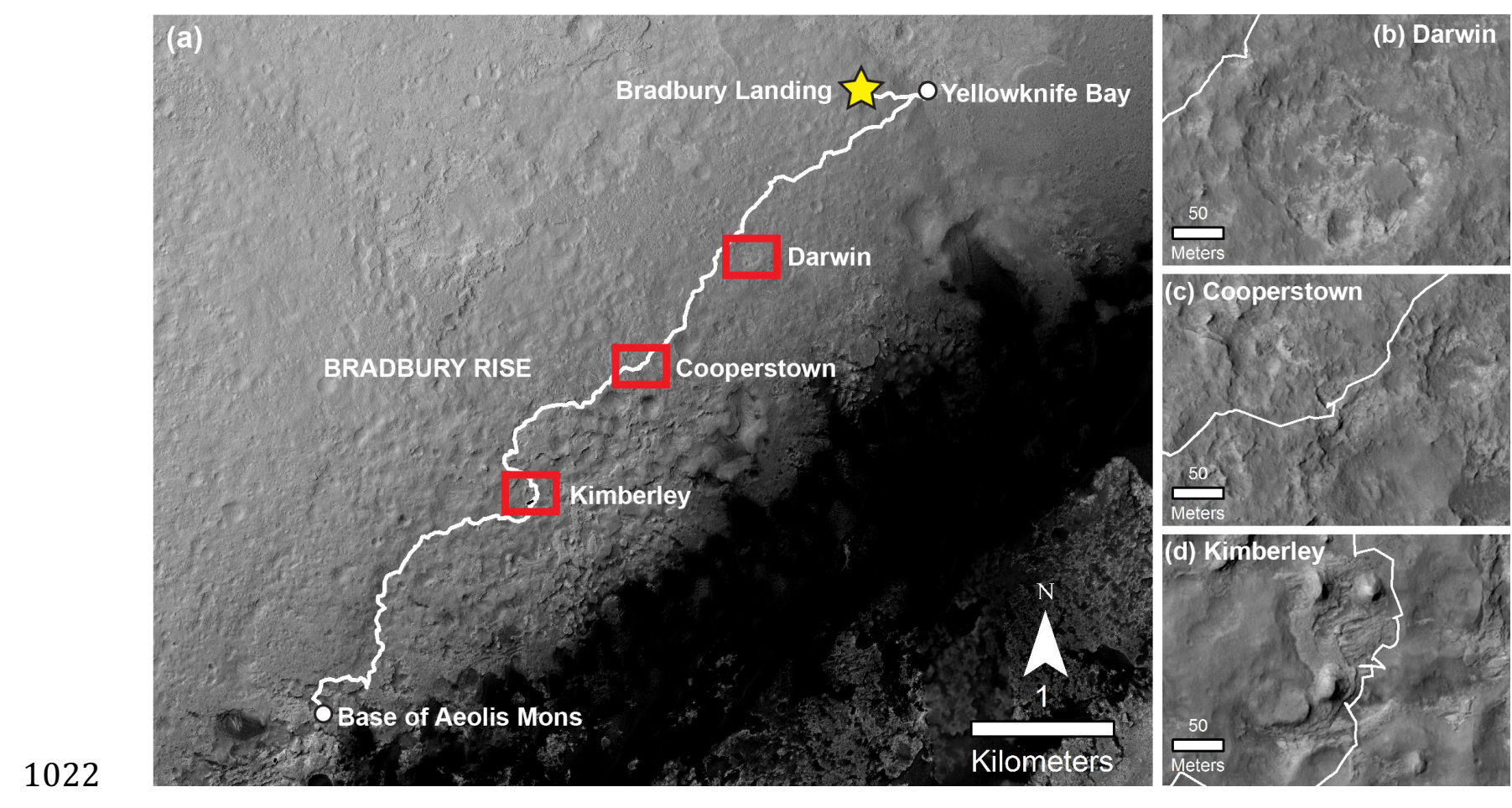

1023 Figure 2. (a) Mosaic of HiRISE images PSP_009505_1755, PSP_010573_1755,

1024 ESP_018854_1755, and PSP_009149_1750) showing the Curiosity rover traverse across

1025 Bradbury Rise and the locations of the Darwin, Cooperstown, and Kimberley waypoints in

1026 relation to Bradbury Landing (yellow star), Yellowknife Bay, and the base of Aeolis Mons.

1027 HiRISE images of the (b) Darwin ( PSP_010573_1755), (c) Cooperstown (PSP_010573_1755),

1028 and (d) Kimberley (ESP_018854_1755) waypoints. Curiosity's traverse is traced by the white 1029 line. 

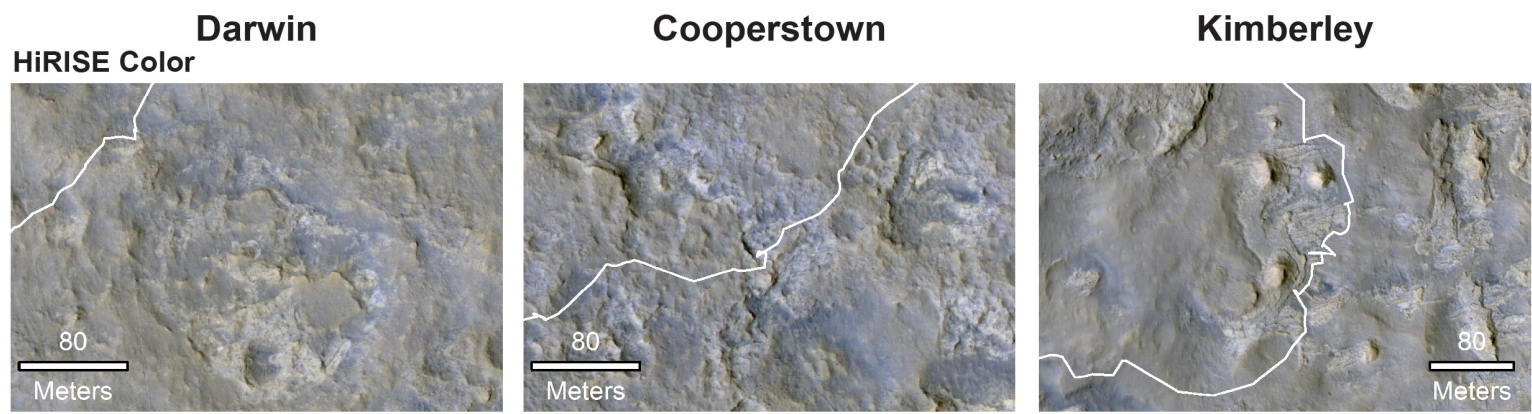

Grotzinger et al. (2014)
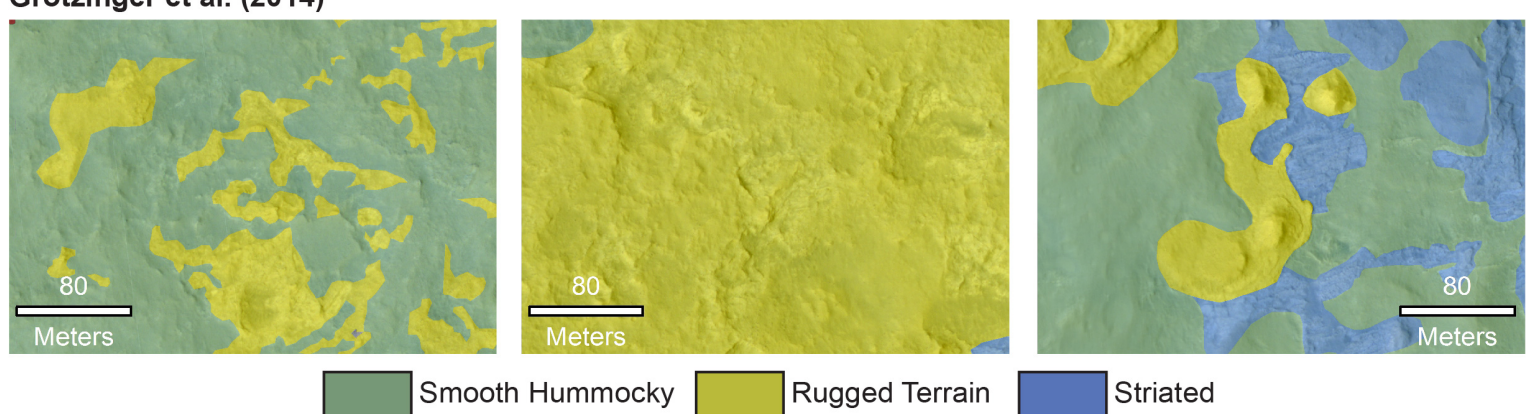

This Study
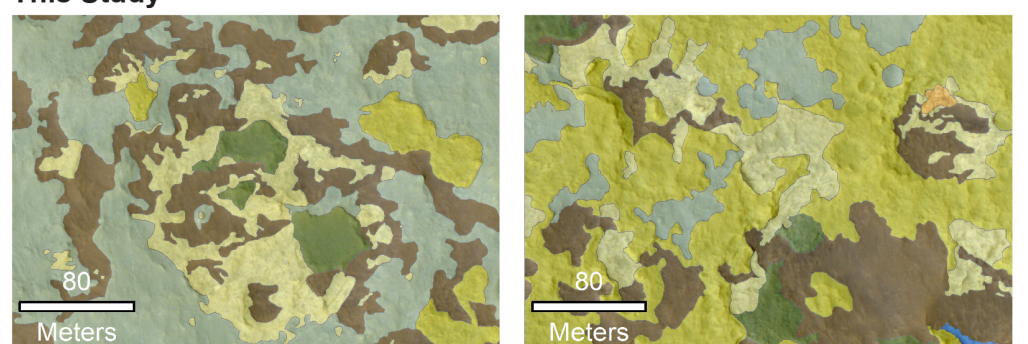

Striated

Figure 3. Previous orbiter image-based mapping of the Darwin, Cooperstown, and Kimberley waypoints by Grotzinger et al. [2014]

1032 compared to this study's orbital maps. The rover traverse is traced by the white line in the HiRISE color images (top row). 


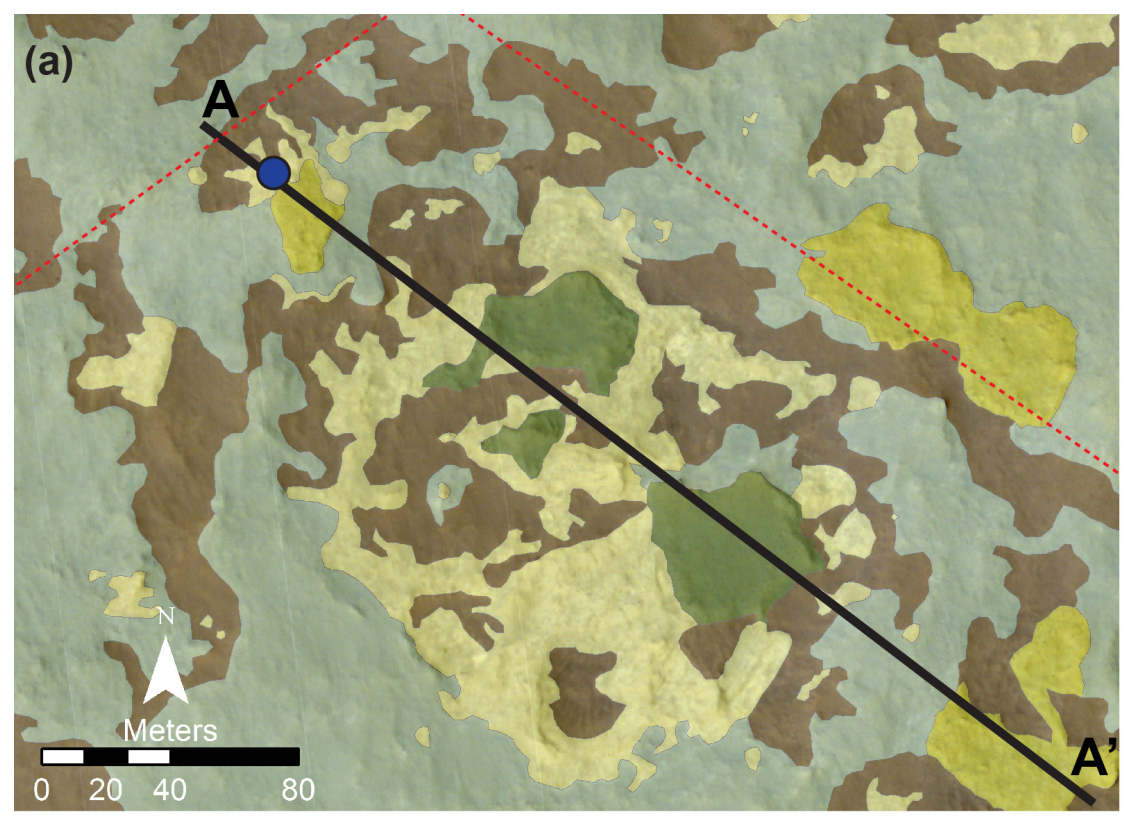

\section{Orbital Facies}

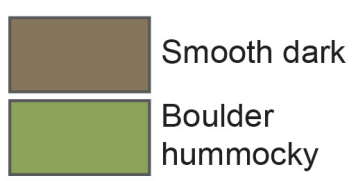

Resistant cratered outcrop

Bright outcrop

Smooth

hummocky

Contact science

location

Mapped extent of

rover mosaic

Contact science section

\section{(b)}

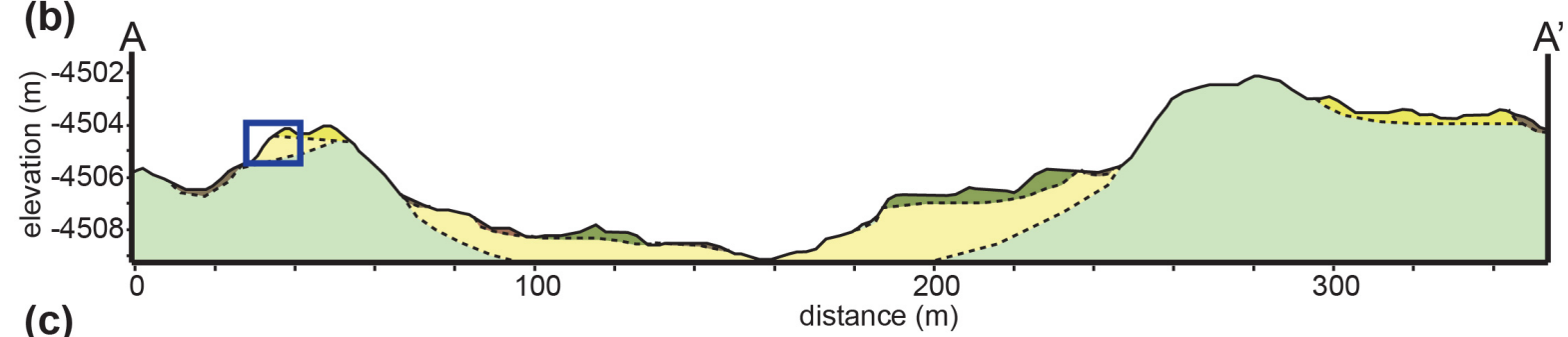

\section{(c)}

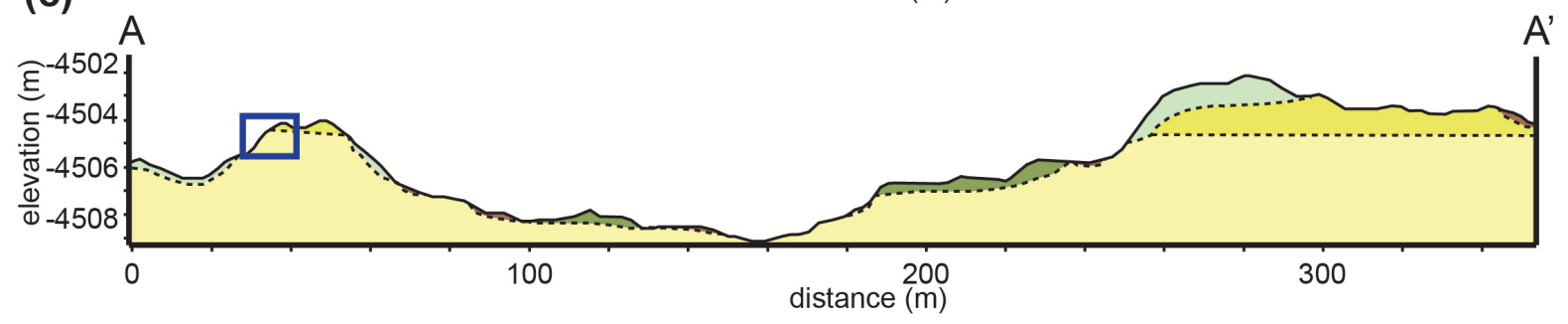

Figure 4. (a) Orbital facies map of the Darwin waypoint and (b-c) cross-section interpretations

1035 representing A to A' displayed with a vertical exaggeration of $6.5 \mathrm{x}$. The rover's location when

1036 the mosaic in Figure 6 was acquired is just north of the mapping area displayed here, and the

1037 area between the two dashed red lines marks the ground coverage of this mosaic in plan view.

1038 The Darwin contact science location shown in Figure 7 is indicated by the blue dot, and is

1039 outlined by the blue boxes in (b) and (c). 

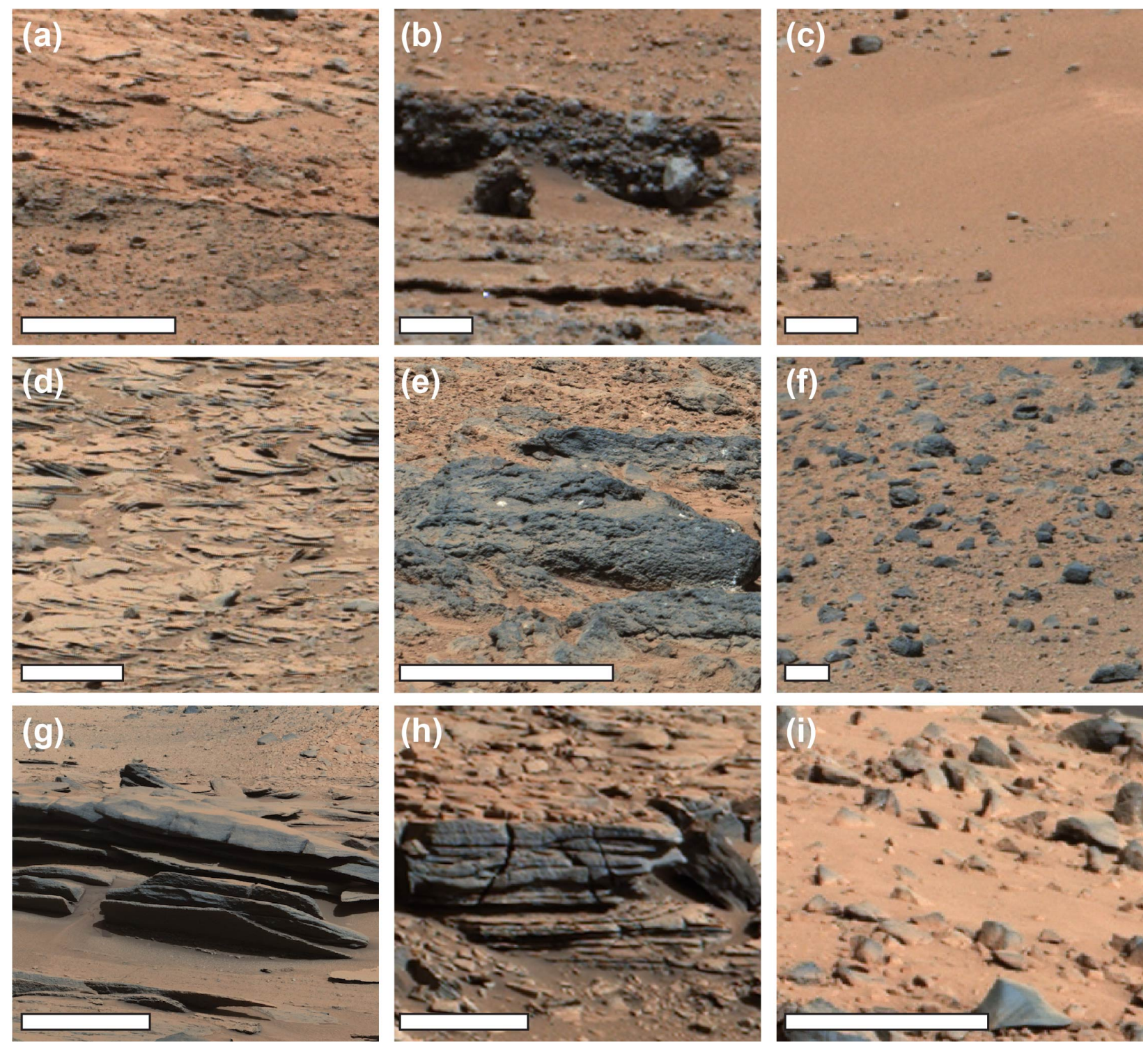

1042 Figure 5. Representative examples of bedrock lithologies and surficial deposits observed in the

1043 M-100 rover mosaics of the (a-c) Darwin, (d-f) Cooperstown, and (g-i) Kimberley waypoints.

1044 Scale bar $=50 \mathrm{~cm}$. Darwin: (a) undifferentiated sandstone and conglomerate, (b) conglomerate,

1045 (c) sand. Cooperstown: (d) platy sandstone, (e) vuggy sandstone, (f) dark float consisting of

1046 boulders and cobbles. Kimberley: (g) south-dipping resistant and recessive sandstones, (h)

1047 bedded sandstone, (i) undifferentiated sand and float. 
(a) Darwin Waypoint Sol 389 Mastcam M-100 Mosaic

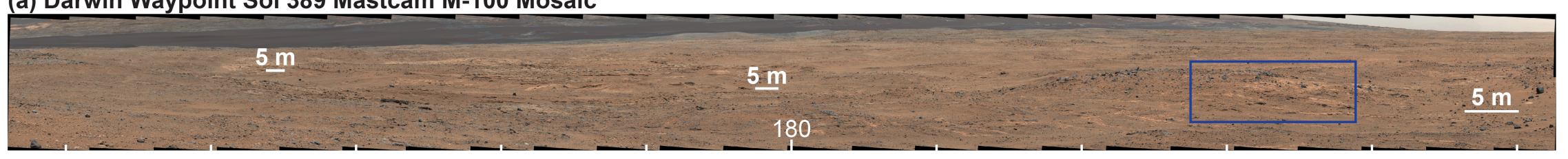

\section{(b) Darwin Orbital Facies}

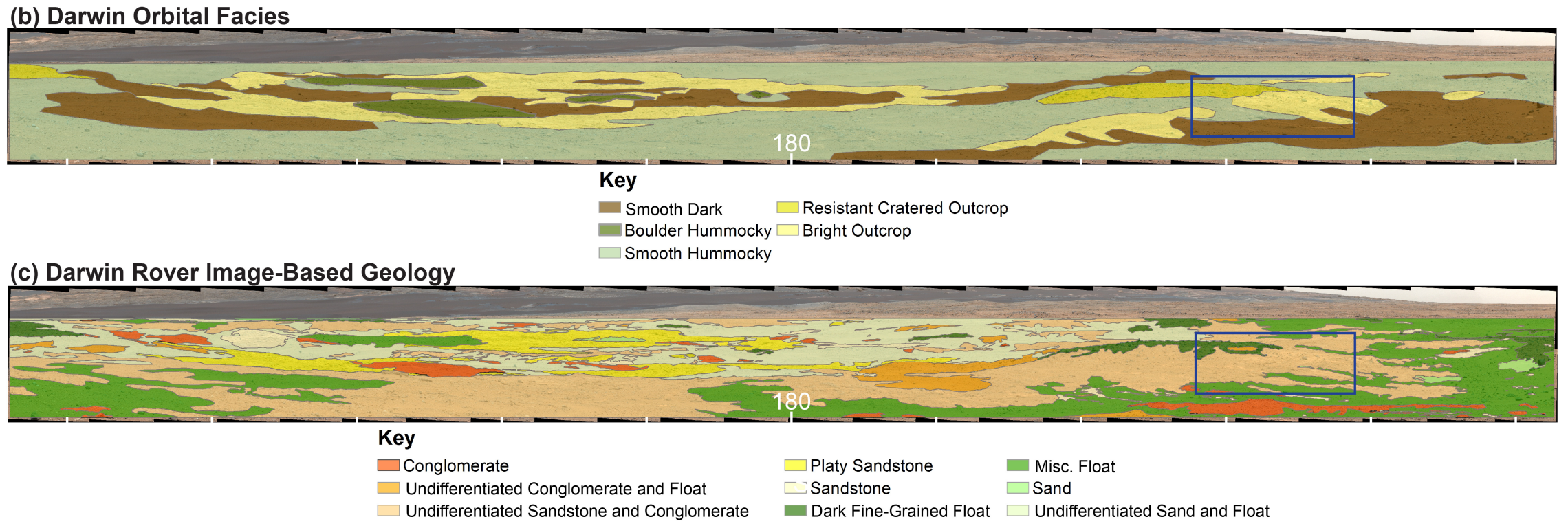

Undifferentiated Sandstone and Conglomerate $\quad$ Dark Fine-Grained Float $\square$ Undifferentiated Sand and Float

1050 Figure 6. Rover mosaic of the Darwin waypoint. (a) Sol 389 Mastcam M-100 Mosaic, The blue box outlines the outcrop shown in

1051 Figure 7 on which the stratigraphic column in Figure 15a is based. White tick marks represent $10^{\circ}$ intervals in azimuth. (b) Mosaic

1052 annotated with mapped orbital facies, (c) Mosaic annotated with rover image-based geology observations. 


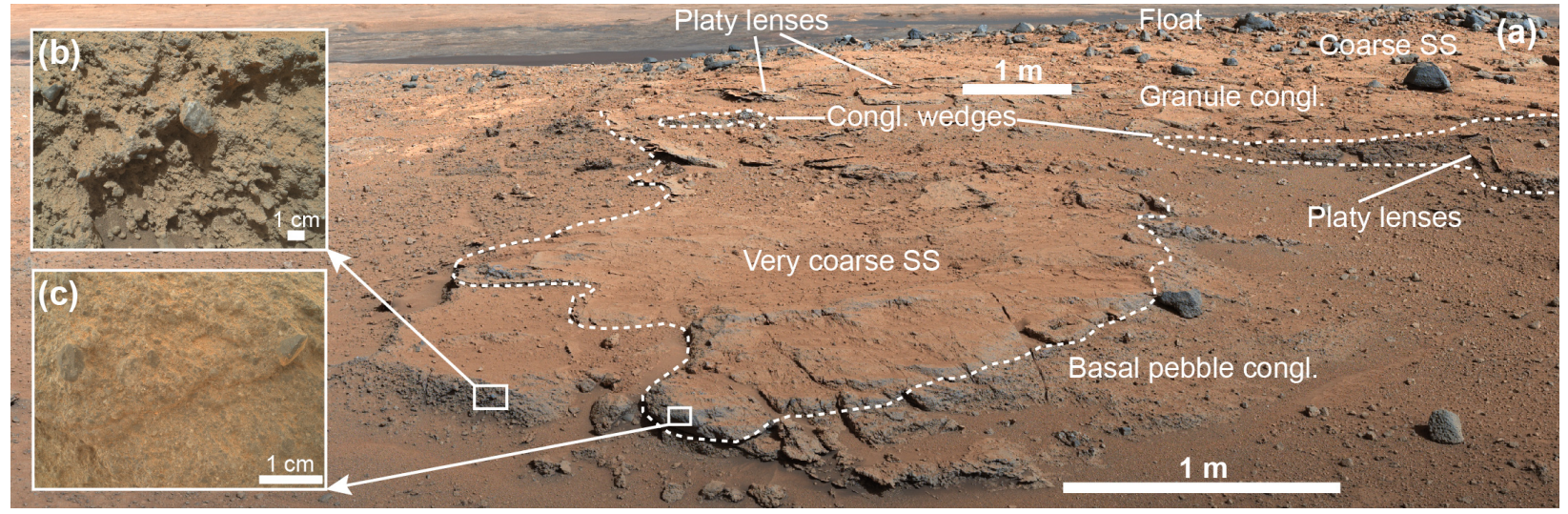

1055 Figure 7. (a) Annotated Mastcam M-34 mosaic acquired on sol 390 showing the location of

1056 Darwin contact science activities represented by the stratigraphic column in Figure 15a. (b)

1057 MAHLI image 0394MH0001900010104439C00 of the Altar Mountain pebble conglomerate

1058 target acquired on sol 394. (c) MAHLI image 0396MH0001700000104468R00 of the Bardin

1059 Bluffs very coarse sandstone acquired on sol 394.

1060

1061

1062

1063

1064 


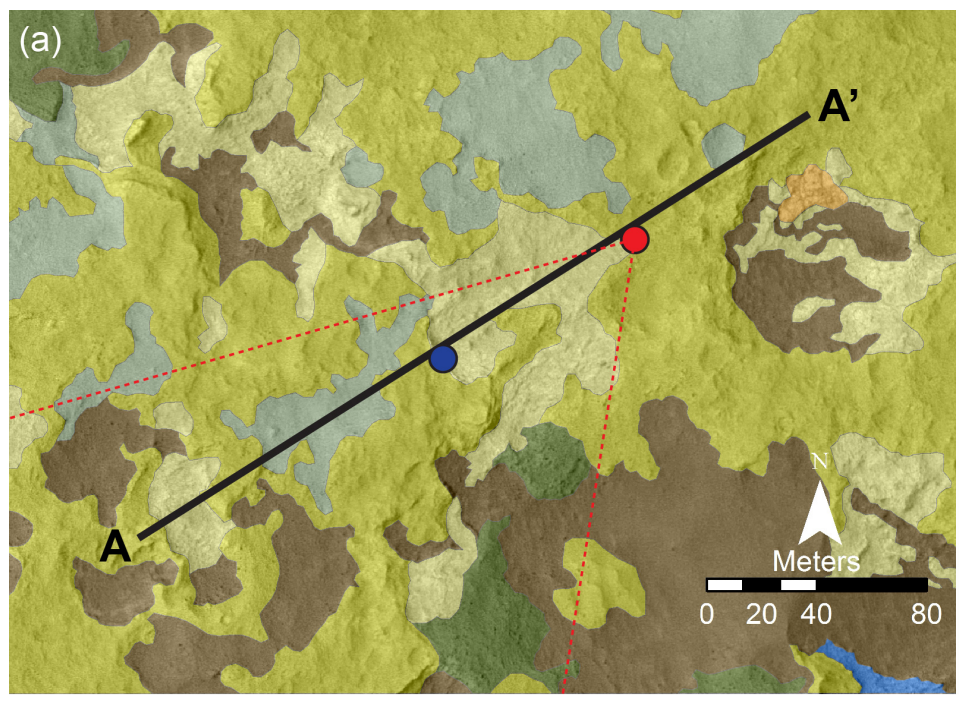

(b)

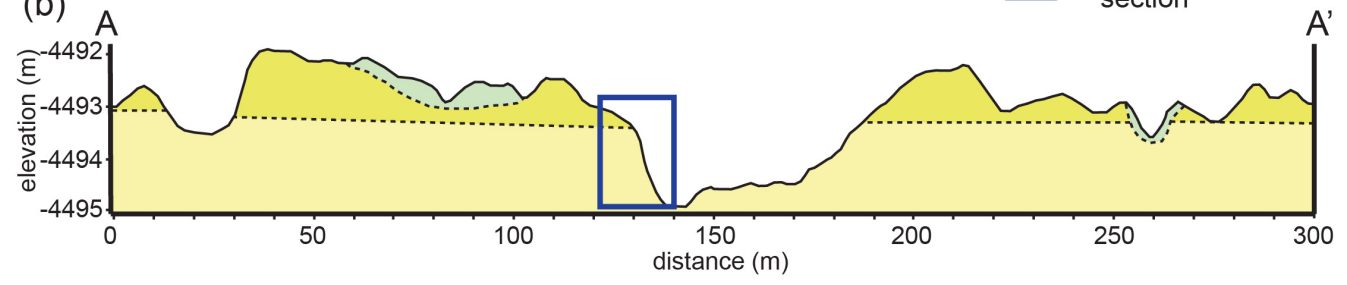

1066 Figure 8. (a) Orbital facies map of the Cooperstown waypoint and (b) cross section

1067 interpretation representing A to A' displayed with a vertical exaggeration of $13 \mathrm{x}$. The red dot in

1068 (a) marks the rover's location when the mosaic in Figure 10 was acquired, and the area between

1069 the two dashed red lines marks the ground coverage of this mosaic in plan view. The location of

1070 the Cooperstown contact science activities shown in Figure 11 is indicated by the blue dot in (a)

1071 and outlined by the blue box in (b).

1072

1073

1074

1075

1076 

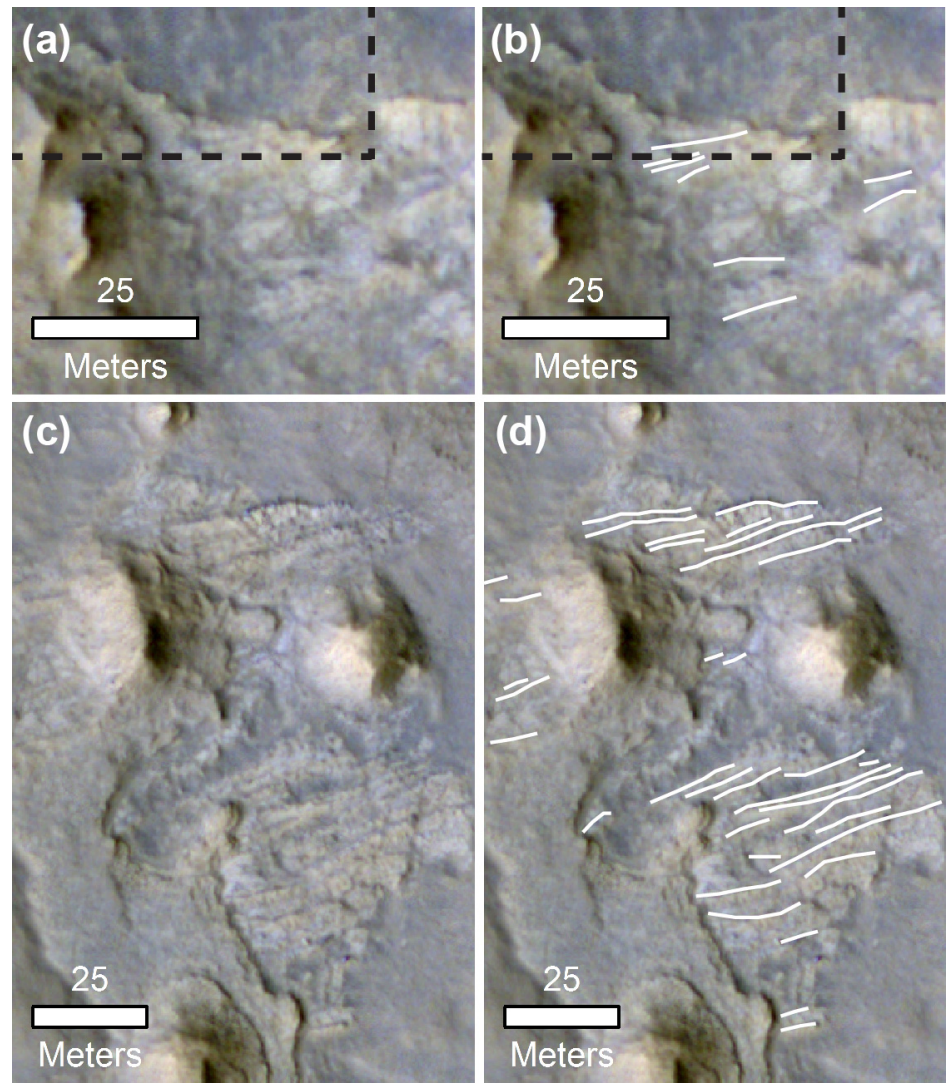

1081 Figure 9. Striations of the bright striated outcrop orbital facies visible in the HiRISE color

1082 mosaic at the (a-b) Cooperstown and (c-d) Kimberley waypoints. (a) Un-annotated close-up of

1083 striations within the bright striated outcrop facies at the Cooperstown waypoint. Dashed black

1084 line outlines the southeastern corner of the Cooperstown mapping area shown in Figure 8. (b)

1085 Same image as (a) with striations traced in white. (c) Un-annotated close-up of striations within

1086 the bright striated outcrop facies at the Kimberley waypoint. (d) Same image as (c) with 1087 striations traced in white. 

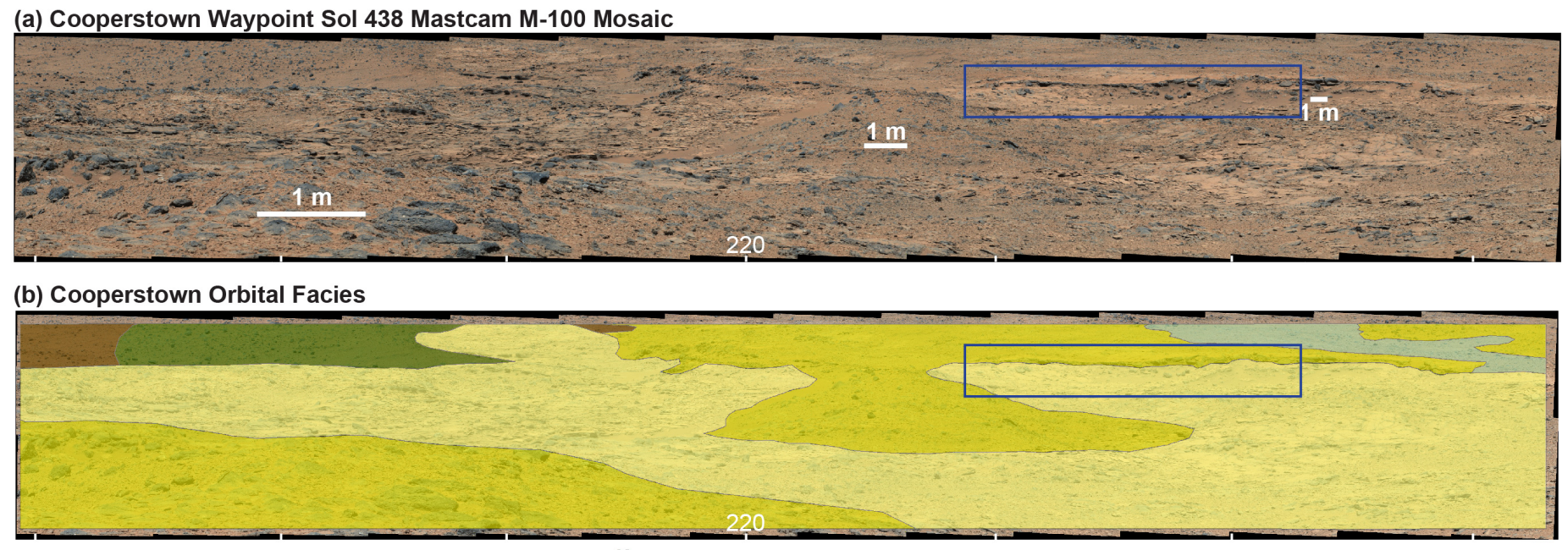

Key

Smooth Dark Boulder Hummocky

(c) Cooperstown Rover Image-Based Geology

$$
\text { Resistant Cratered Outcrop }
$$
Bright Outcrop

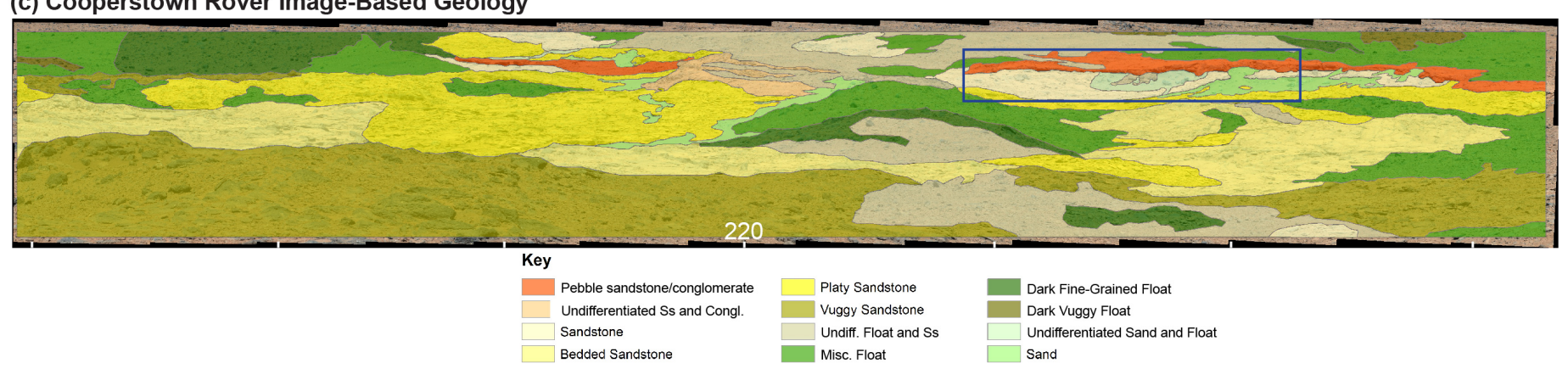

1089 Figure 10. Rover mosaic of the Cooperstown waypoint. (a) Sol 438 Mastcam M-100 Mosaic, The blue box shows the portion of the

1090 Darwin outcrop shown in Figure 11 and represented by the stratigraphic column in Figure 15b. White tick marks represent $10^{\circ}$

1091 intervals in azimuth. (b) Mosaic annotated with mapped orbital facies, (c) Mosaic annotated with rover image-based geology

1092 observations. 


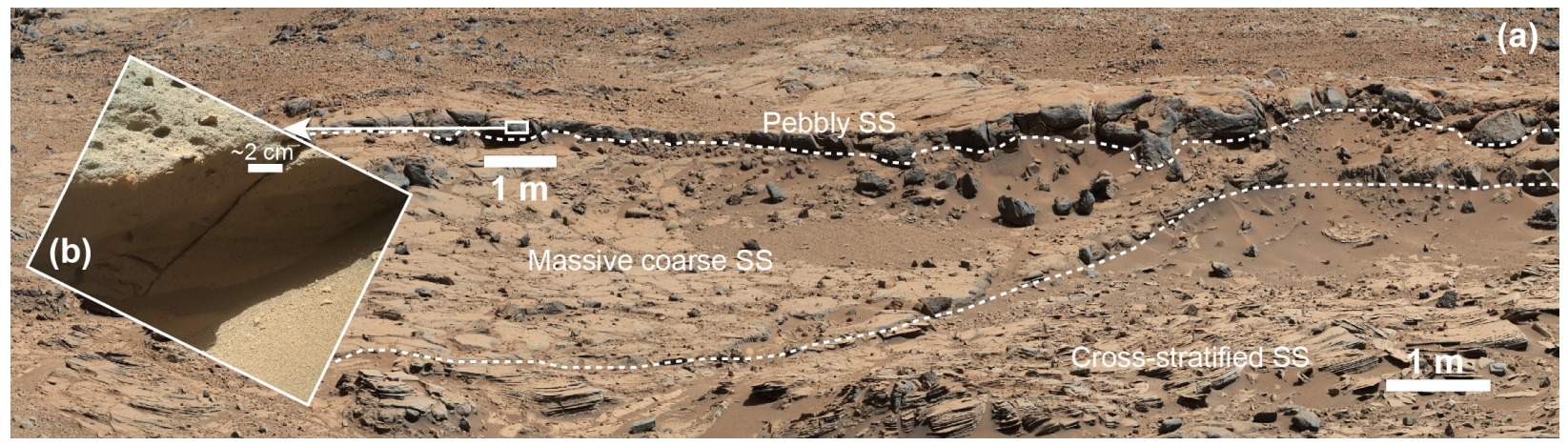

1094 Figure 11. (a) Annotated Mastcam M-100 mosaic acquired on sol 439 showing the Cooperstown

1095 outcrop represented by the stratigraphic column in Figure 15b. (b) MAHLI image

1096 0443MH0003290000200185R00 taken near the Renssalaer target acquired on sol 443.

1097

1098

1099 

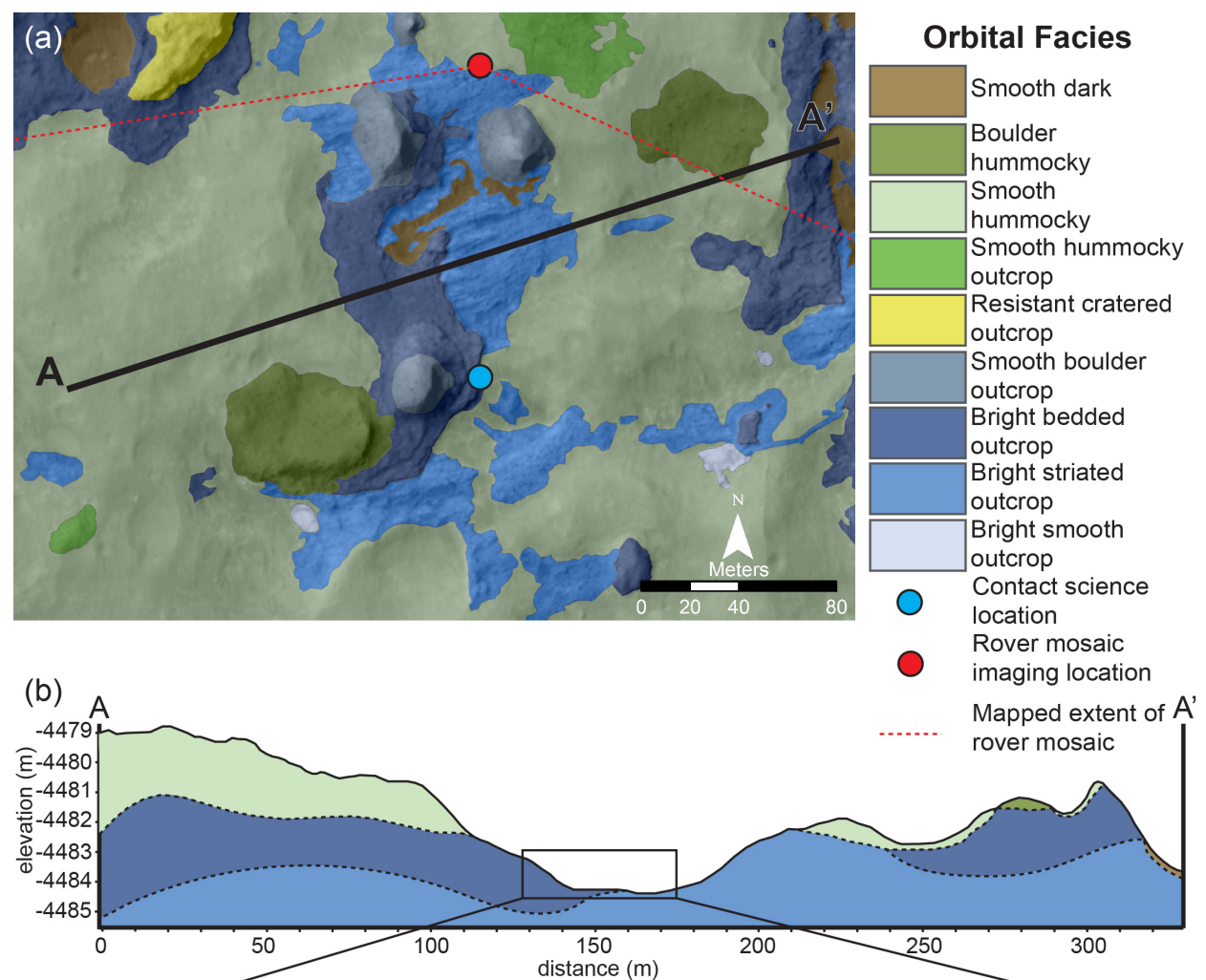

(c)

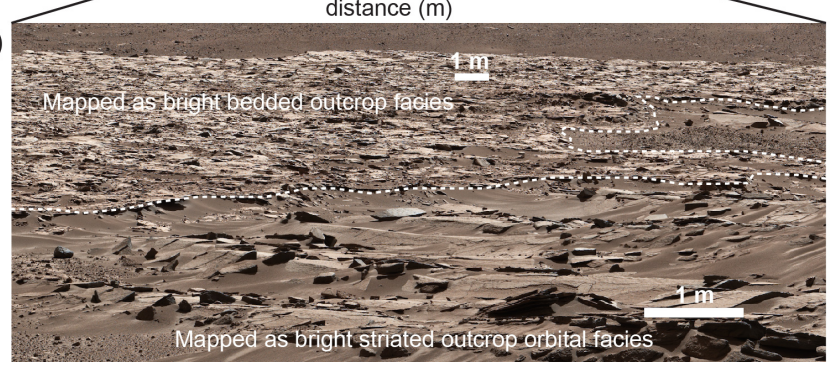

1101 Figure 12. (a) Orbital facies map of the Kimberley waypoint and (b) cross section interpretation

1102 representing A to A' displayed with a vertical exaggeration of 9x. The red dot indicates the

1103 rover's location when the mosaic in Figure 13 was acquired, and the two dashed red lines mark

1104 the ground coverage of this mosaic in plan view. The blue dot indicates the Windjana contact

1105 science and drill location shown in Figure 14 that was used to construct the stratigraphic section

1106 in Figure 15c. Since the cross-section does not cross this location, no annotation of the section is

1107 shown in (b). (c) Portion of a Mastcam M-100 mosaic obtained on Sol 595 showing the rover's

1108 view of the contact mapped in HiRISE between the bright striated outcrop facies and the bright

1109 bedded outcrop facies. 
(a) Kimberley Waypoint Sols 580 and 582 Composite Mastcam M-100 Mosaic

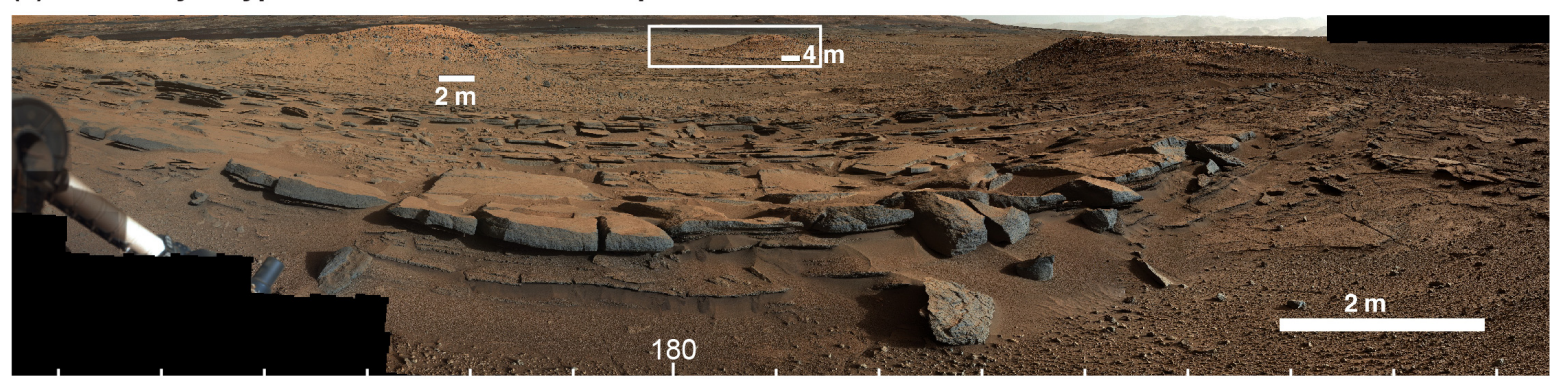

(b) Kimberley Orbital Facies

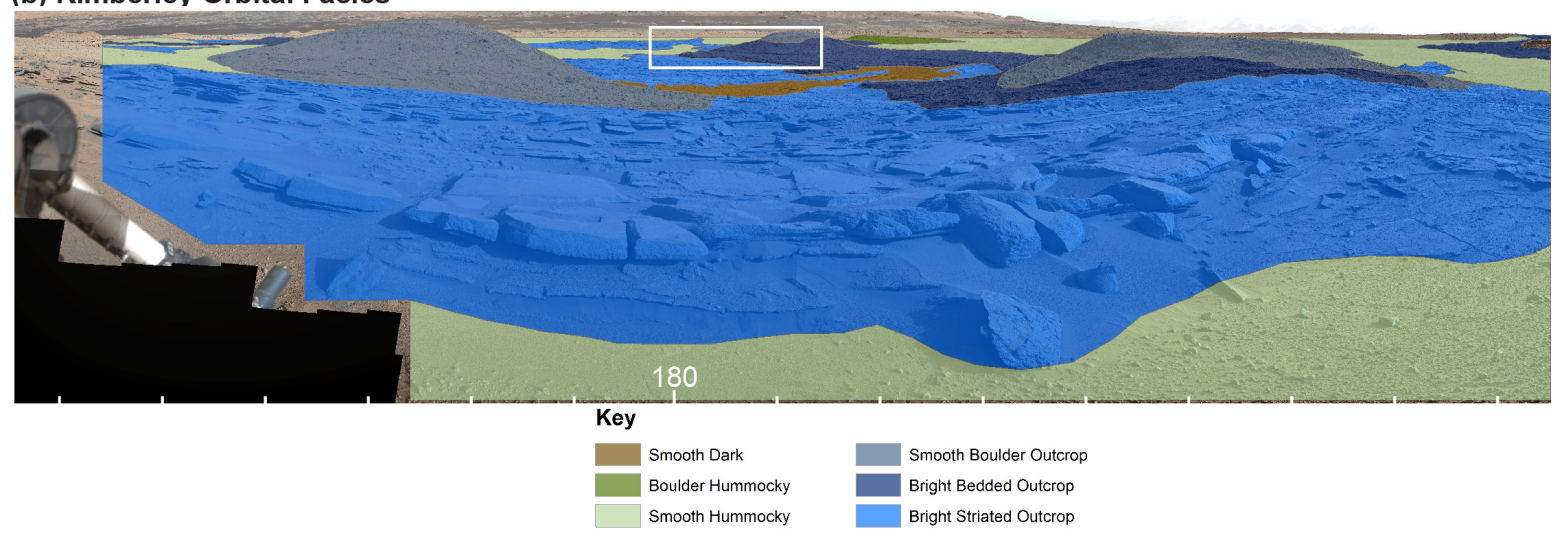

(c) Kimberley Rover Image-Based Geology

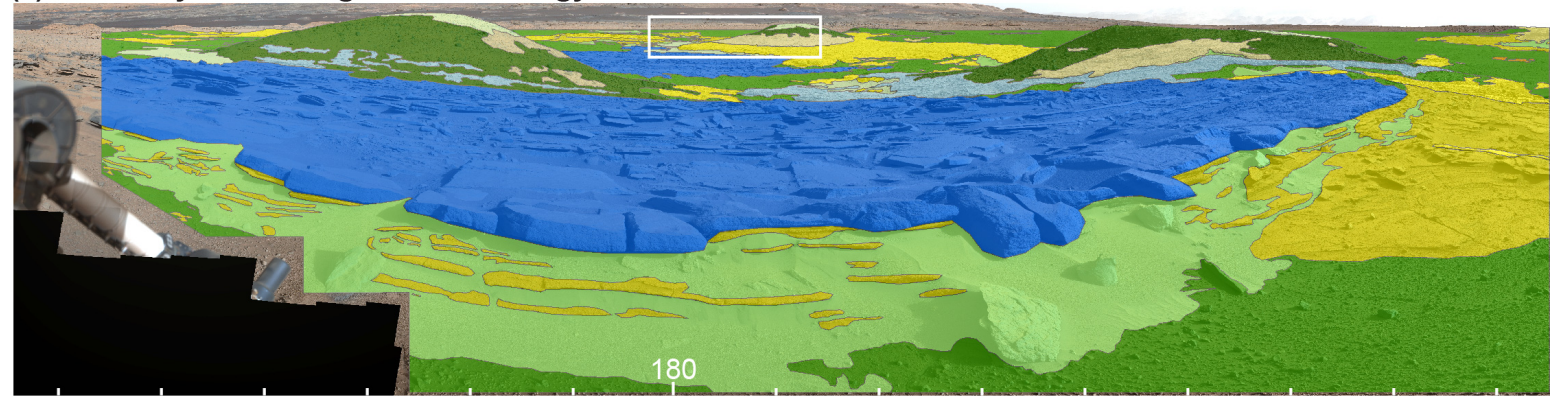

Key

\begin{tabular}{l|l} 
Conglomerate & Fine-grained Platy Sandstone \\
\hline
\end{tabular}

Coarse Massive San

\begin{tabular}{ll|l} 
NW-dipping Fine-grained Platy Sandstone & Undifferentiated \\
\hline & Misc. Float
\end{tabular}

South-dipping Fine-grained Platy Sandstone

Undifferent

Sand

1111 Figure 13. Rover mosaic of the Kimberley waypoint. (a) Sol 580 Mastcam M-100 Mosaic. The

1112 white box outlines the outcrop shown in Figure 14. White tick marks represent $10^{\circ}$ intervals in

1113 azimuth. (b) Mosaic annotated with mapped orbital facies. (c) Mosaic annotated with gorund-

1114 based rover geology observations. 


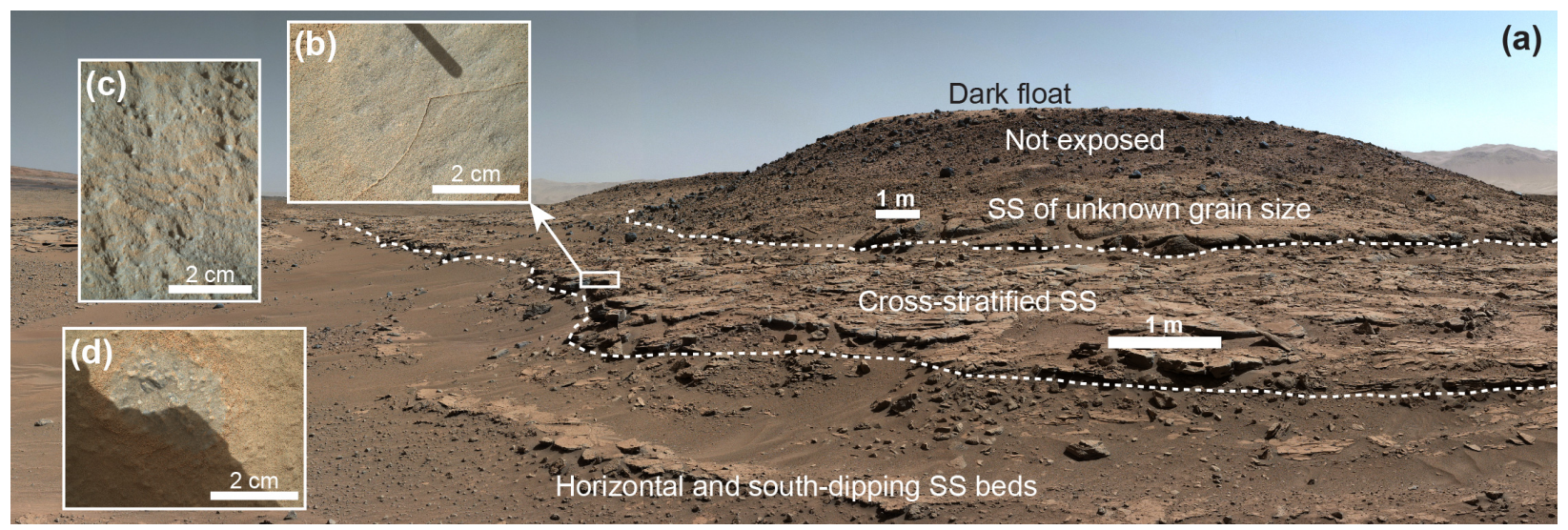

1116 Figure 14. (a) Annotated Mastcam M-34 mosaic of Mount Remarkable acquired on sol 603

1117 showing the outcrop represented by the stratigraphic column in Figure 15c. (b) MAHLI image

1118 0612MH0001930000203350R00 of the very-fine sandstone at the Winjana brushed target

1119 acquired on sol 612. (c) MAHLI image 0585MH0002970010202808C00 of a coarse-grained

1120 south-dipping sandstone bed taken near the Square Top target (location not shown in this

1121 mosaic) on sol 585. (d) MAHLI image 0601MH0003810000203227R00 of the coarse granule

1122 sandstone of the Liga target (location not shown in this mosaic) acquired on sol 601. 


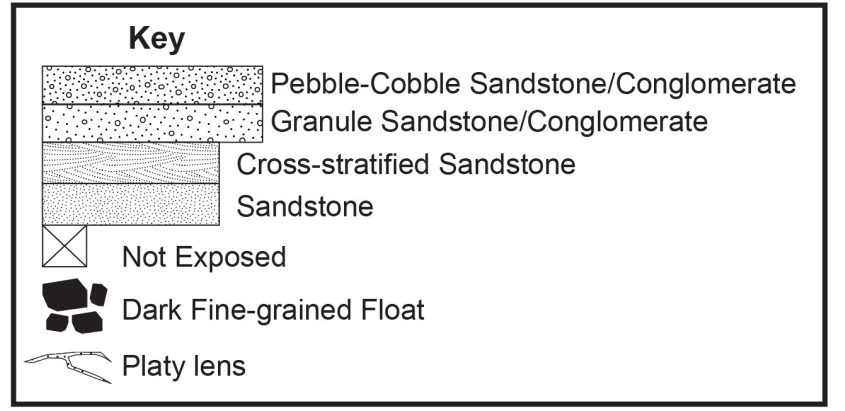

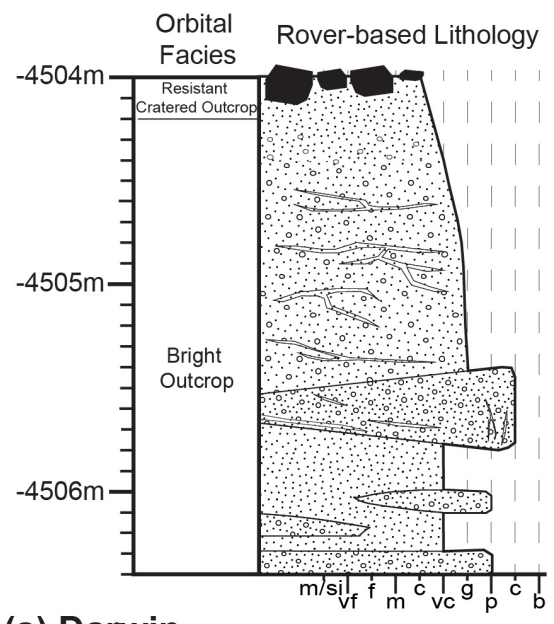

(a) Darwin

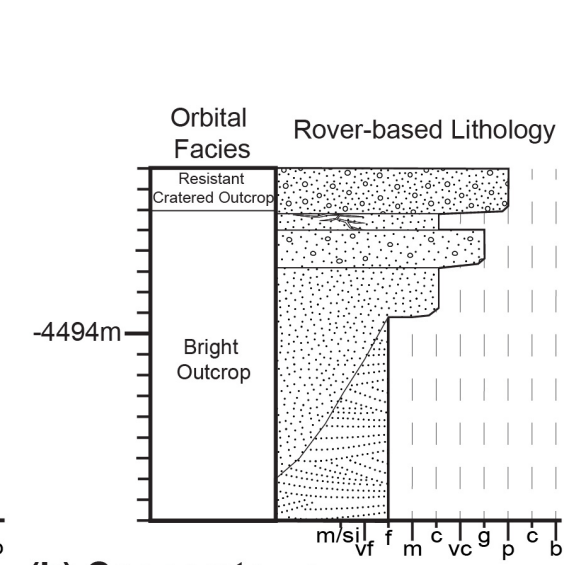

(b) Cooperstown

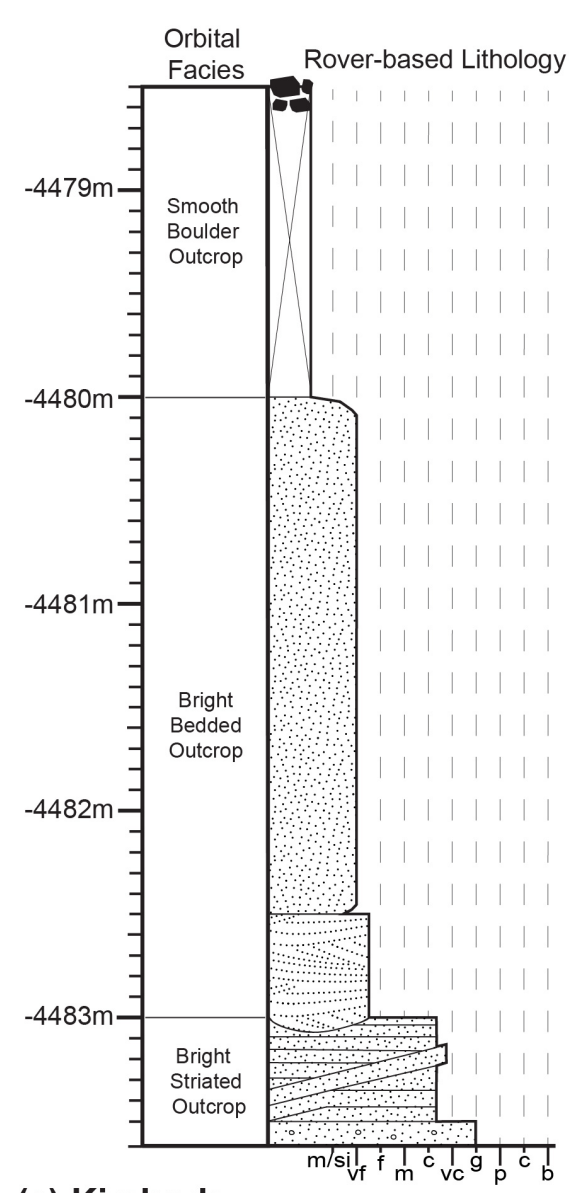

(c) Kimberley

1124 Figure 15. Stratigraphic columns showing mapped orbital facies interpreted as stratigraphic units compared with equivalent rover

1125 observations of bedrock lithology for (a) Darwin, (b) Cooperstown, and (c) Kimberley. 

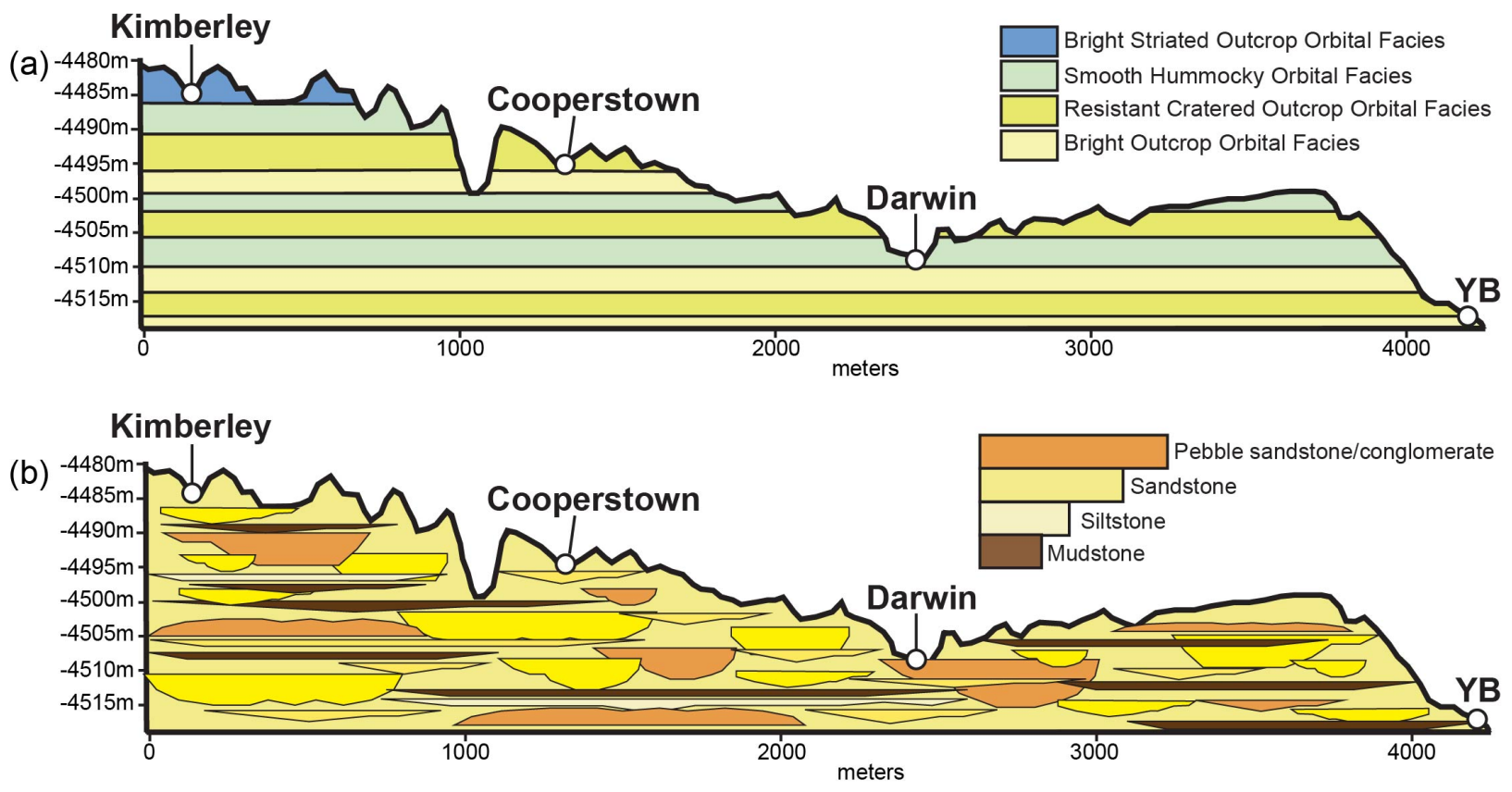

1127 Figure 16. Schematic cross-sections showing (a) Bradbury Rise stratigraphy interpretation

1128 derived from orbital mapping, and (b) the ground-based fluvial/alluvial depositional

1129 interpretation of Bradbury Rise. The topography shown in both profiles is derived from a

1130 HiRISE DTM. Sections in (a) and (b) are displayed with a vertical exaggeration of 22x. 